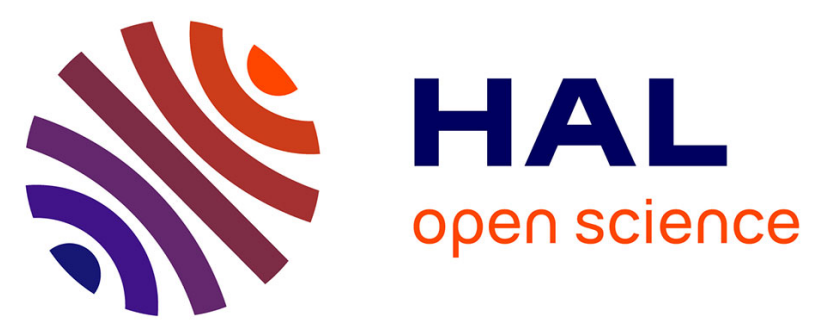

\title{
SMART 2013: Experimental and numerical assessment of the dynamic behavior by shaking table tests of an asymmetrical reinforced concrete structure subjected to high intensity ground motions
}

\author{
Benjamin Richard, Stefano Cherubini, François Voldoire, Pierre-Etienne \\ Charbonnel, Thierry Chaudat, Salim Abouri, Nicolas Bonfils
}

\section{To cite this version:}

Benjamin Richard, Stefano Cherubini, François Voldoire, Pierre-Etienne Charbonnel, Thierry Chaudat, et al.. SMART 2013: Experimental and numerical assessment of the dynamic behavior by shaking table tests of an asymmetrical reinforced concrete structure subjected to high intensity ground motions. Engineering Structures, 2016, 109, pp.99-116. 10.1016/j.engstruct.2015.11.029 . hal-01634196

\author{
HAL Id: hal-01634196 \\ https://hal.science/hal-01634196
}

Submitted on 2 Dec 2019

HAL is a multi-disciplinary open access archive for the deposit and dissemination of scientific research documents, whether they are published or not. The documents may come from teaching and research institutions in France or abroad, or from public or private research centers.
L'archive ouverte pluridisciplinaire HAL, est destinée au dépôt et à la diffusion de documents scientifiques de niveau recherche, publiés ou non, émanant des établissements d'enseignement et de recherche français ou étrangers, des laboratoires publics ou privés. 


\title{
SMART 2013: Experimental and numerical assessment of the dynamic behavior by shaking table tests of an asymmetrical reinforced concrete structure subjected to high intensity ground motions
}

\author{
Benjamin Richard $^{\mathrm{a}, *}$, Stefano Cherubini ${ }^{\mathrm{a}}$, François Voldoire ${ }^{\mathrm{b}, \mathrm{d}}$, Pierre-Etienne Charbonnel ${ }^{\mathrm{a}}$, \\ Thierry Chaudat ${ }^{\mathrm{a}}$, Salim Abouri ${ }^{\mathrm{c}}$, Nicolas Bonfils ${ }^{\mathrm{c}}$ \\ ${ }^{a} C E A, D E N$, DANS, DM2S, SEMT, Laboratoire d'Etudes de Mécanique Sismique, F-91191 Gif-sur-Yvette, France \\ ${ }^{\mathrm{b}}$ EDF, DRED, Acoustics and Mechanical Analysis Department, 1, avenue du Général de Gaulle, F-92141 Clamart, France \\ ${ }^{\mathrm{C}}$ EDF, SEPTEN, Dynamic and Earthquake Engineering Group, 12-14, avenue Dutriévoz, F-69628 Villeurbanne, France \\ ${ }^{\mathrm{d}}$ Institute of Mechanical Sciences and Industrial Applications, EDF-CNRS-CEA-ENSTA UMR 9219, 1, avenue du Général de Gaulle, F-92141 Clamart, France
}

As part of a large research program launched and funded by the French Atomic Energy and Sustainable Energies Commission (CEA) and Electricité De France (EDF), partially supported by the International Atomic Energy Agency (IAEA) and entitled "Seismic design and best-estimate Methods Assessment for Reinforced concrete buildings subjected to Torsion and nonlinear effect (SMART)", a series of shaking table tests on a $1 / 4$-scale 3 -story reinforced concrete model characterized by a strong asymmetry has been carried out in July 2013. The seismic loading was composed of three test sequences having different peak ground accelerations (PGA): the design level signal (PGA equal to $0.2 \mathrm{~g}$ ), the Northridge main shock signal (PGA equal to $1.78 \mathrm{~g}$ ) and a Northridge aftershock (PGA equal to $0.33 \mathrm{~g}$ ). In this paper, the main experimental results, compared with outputs from a numerical study carried out by CEA, are presented and discussed. The following conclusions were reached for each seismic test sequence: (i) only small nonlinearities appeared and both displacement and acceleration-based quantities were properly estimated by the model; (ii) the specimen exhibited moderate nonlinearities in case of PGA higher than 4 or 5 times the design PGA; displacements were numerically underestimated whereas maximum acceleration-based quantities were captured rather well; (iii) the fact that no additional damage was monitored during this seismic sequence was pointed out only by the experimental measurements but also by the numerical outputs, leading to show that this aftershock signal did not induce any further damage. Given the aforementioned observations, it was possible to carry out a robustness analysis based upon two damage indicators: the eigenfrequency shift and the inter-story drift. Apart from the issues of the most meaningful robustness indicator and the choice of damage thresholds that came up, it is shown that the specimen can be qualified as being robust.

\section{Introduction}

Natural disasters are the consequence of natural hazards, such as tornados, volcanic eruptions, landslides, tsunamis or earthquakes, which cause millions of deaths and severe socioeconomic constraints, which impact the development of many countries. This perspective is particularly true when dealing with energy production plant buildings which need to be designed to safely withstand the most severe environmental conditions that could reasonably be expected to affect them during their lifetime.

\footnotetext{
* Corresponding author.

E-mail address: Benjamin.Richard@cea.fr (B. Richard).
}

The nuclear industry encourages the international scientific community to undertake ambitious research programs aimed at improving knowledge in several fields and thus ensuring the safety of nuclear power plants. Within this context, the field of earthquake engineering has taken important steps to better understand how complex reinforced concrete (RC) structures behave when subjected to a seismic loading.

Identified as having the potential to withstand severe damage, RC shear walls have been extensively studied worldwide since the 70's. Many research programs aimed at studying the structural behavior of isolated shear walls under static loading have been undertaken [1-10]. The experimental data produced reveal that shear walls have a high bearing capacity when subjected to static 
loadings. Shear walls are generally not used as isolated components but rather are included and connected with other components: this major fact that has not yet been fully analyzed. The specific structural effects of such use must be understood. Additional experimental investigations focused on shear walls with end walls [11-16] or walls framed with beams and columns $[17,18]$ under static loadings. Structural effects due to assembly between each component appeared to be significant. Then, experimental investigations were carried out on a three-dimensional shear walls assembly $[19,20]$, mainly with a symmetrical geometry not only in-plane but also in elevation and tested under static conditions. In order to assess the capabilities of shear walls based structures to withstand seismic loadings, experimental studies with a dynamic loadings factor have been carried out. Nevertheless, the difficulties of applying a dynamic loading where the inertia force field is reproduced, to a RC specimen make experimental data rare in scientific literature, in particular, when such a loading condition is applied to a three-dimensional model of shear walls based structure. Experiments where an impulsive loading was considered to analyze the fundamental dynamic properties of structures are available in literature [21,22]. A few scientific works where a full three-dimensional structural model was subjected to a dynamic load $[23,24]$ are also reported in literature. In 2010, a wide experimental campaign was carried out at the University of California in San Diego (UCSD). A symmetric seven-story RC shear wall based structure was subjected to uniaxial shaking table tests of increasing intensity [25-29]. This test was carried out within the framework of an international benchmark aiming at comparing various modeling strategies and identifying the benefits and limitations under a blind condition. This experimental campaign led to fruitful conclusions regarding the identification of model uncertainties and the definition of further needs of large-scale testing [30]. In 2006, the French Atomic Energy and Sustainable Energies Commission (CEA) and Electricité De France (EDF) began a wide research program entitled Seismic design and best-estimate Methods Assessment for Reinforced concrete buildings subjected to Torsion and nonlinear effect (SMART) [31,32]. In 2008, a large experimental campaign was launched to carry out seismic tests on an asymmetric reduced scale model of a RC wall based structure by means of the AZALEE shaking table operated by the Nuclear Energy Division (DEN) at the CEA center located in Saclay (France). It was called SMART 2008. Synthetic seismic loadings with increasing intensities were applied to the RC specimen: the main aim was to quantify the seismic margin with respect to the design level. It has been clearly shown that there are seismic margins. A welldocumented experimental data-base was set up for the aim of validating numerical simulation methodologies for engineering purposes and for setting a basis for a benchmark exercise in that field [33].

Despite the improvements made, several questions are still unanswered and such that the CEA and EDF began a new experimental program in 2011, called SMART 2013, which is partially supported by the International Atomic Energy Agency (IAEA); in this program, the same type of wall-based asymmetrical structure as that part of the SMART 2008 program is being tested. The aims of this new experimental program are to improve the representativeness of the seismic loading regarding real seismic scenarios and to better quantify the effects of nonlinearities and torsion on the dynamic response of the equipment and secondary structures. In addition, in order to feed the numerical models, the monitoring of boundary conditions during shaking table tests was given special attention. Reference data created within the framework of the SMART 2013 experimental campaign were used to feed an International Benchmark. This paper is dedicated to the presentation of the SMART 2013 experimental campaign. The main results are presented and discussed; to enrich discussions, they are supported by some experimental/numerical comparisons.

This paper is outlined as follows. First of all, the experimental campaign and the numerical model developed by the CEA to support the measurements are presented. The test specimen and the material properties of concrete and steel are depicted. The instrumentation arrangement is briefly described before presenting the seismic loading procedure. Then, the main features of the numerical model are described: the finite element mesh, the constitutive laws and the boundary conditions, etc. The problem solving methodology is also addressed. The results from the computation of the initial dynamic properties (eigenfrequencies and modeshapes are compared with the experimental ones). Then, some results present the basis on which the dynamic behavior of the $\mathrm{RC}$ specimen can be assessed. Especially, the degradation process of the specimen along the different seismic loadings is presented. In addition, structural responses based on the analysis of acceleration and displacement-based on quantities during the seismic loadings are presented. The dynamic responses of a pipeline located on the RC specimen are also presented and discussed. A focus is made on the dynamic behavior of the equipment by comparing a global model, included in the overall finite element model in a first approach, with a refined model, developed in a second approach so as to better understand its behavior. Third, the robustness of the RC specimen regarding the damaging seismic scenario considered within the framework of SMART 2013 experimental campaign is quantified and the results are discussed.

\section{Experimental and numerical backgrounds}

\subsection{Experimental campaign}

\subsubsection{Test specimen and material properties}

The RC specimen is a scaled model of a simplified half part of a nuclear electrical building. It has been prepared to reproduce the geometrical, physical and dynamical characteristics of a part of the real building. Due to the inherent limitations related to the laboratory's capacity, regardless of the laboratory in question, some simplifying assumptions have to be considered. In particular, considering the size or the mass of the real building and the load capacity of the AZALEE shaking table [34], the model had to be geometrically reduced to a scale equal to $1 / 4$. The well-known CauchyFroude similitude law was chosen in this experiment. This choice ensures that both the acceleration and the stress fields remain unchanged throughout the scale change if the following conditions are met: the frequencies are multiplied by a factor 2 , the mass is multiplied by a factor 4 and the time is divided by a factor 2 . The RC specimen was designed according to the current French design rules to be considered when dealing with a nuclear building $[35,36]$. The design spectrum considered is shown in Fig. 1. It corresponds to an earthquake magnitude equal to 5.5 at a distance of $10 \mathrm{~km}$ from the failure plane. The peak ground acceleration (PGA) is $0.2 \mathrm{~g}$. Synthetic accelerograms were generated from the design spectrum and the corresponding acceleration response spectra are compared to the design spectra in Fig. 1. A detailed description of the generation technique used can be found in [37]. A satisfactory agreement between the design spectra and the response spectra derived from synthetic signals can be pointed out.

The geometry of the RC specimen was defined in order to meet the following conditions: (i) the specimen should have an asymmetric shape to ensure significant torsional effects during the loading and (ii) the first eigenfrequencies should be in the range $4-10 \mathrm{~Hz}$ to ensure that significant damage appears and that the specimen is representative of existing nuclear buildings currently operated in France. A picture of the test specimen is exposed 


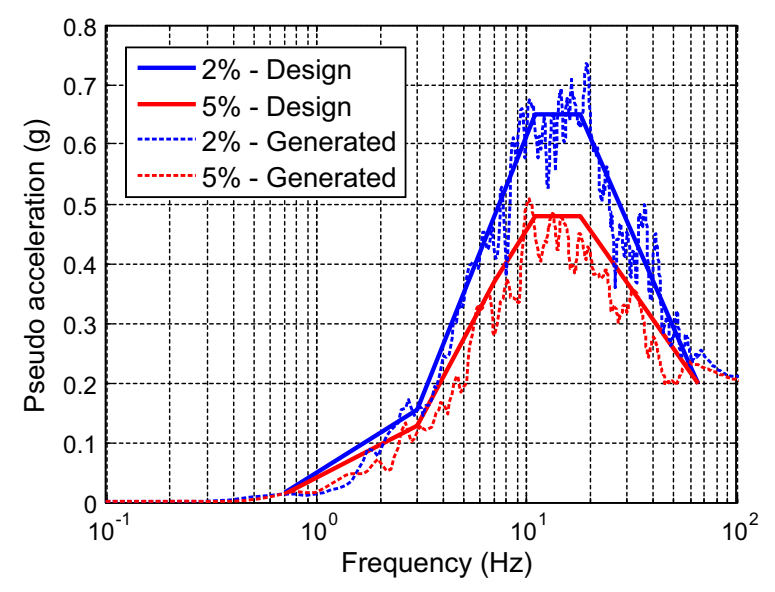

Fig. 1. Comparison between design spectrum and response spectra for the generated input ground motions - $2 \%$ and $5 \%$ damping - magnitude equal to 5.5 .

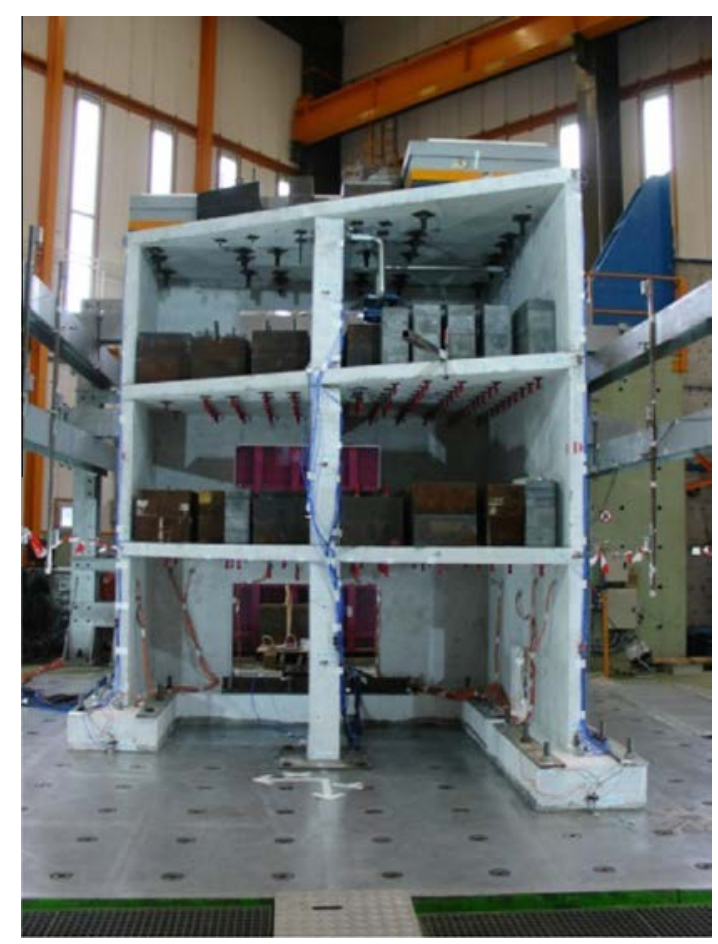

Fig. 2. Picture of the SMART 2013 fixed on the AZALEE shaking table ready to be tested.

in Fig. 2. It is composed of nine structural elements: one foundation, three shear walls (referenced as shear wall \#1 to \#4 in the in-plane view of the formwork drawings presented in Fig. 3), three slabs, three beams and one column. In order to avoid any potential differential displacements, a new anchorage and foundation design was considered with respect to the former SMART 2008 specimen. The continuous RC footing is $650 \mathrm{~mm}$ wide and $250 \mathrm{~mm}$ high; it is bolted on 34 anchoring points in a 20 -mm-thick steel plate; planarity defaults are mitigated by means of a mortar layer against the steel plate which is fastened to the shaking table. Uniformly distributed additional masses are clamped on the mock-up slabs (apart from on the RC beams) to ensure the condition related to the similitude rule; the total mass of the RC specimen is then equal to 45.69 tons.

In order to illustrate the local behavior of typical equipment that can be found in a nuclear building, a reduced scale ( $1 / 4$ scale specimen adapted from the initial piping model of ELSA experimental program [38]) pipe line has been included at the second level of the RC specimen. It is composed of five parts with different lengths made of 304L stainless steel; it is anchored at both extremities on the RC structure, on the third story. No fluid is put into the pipe. A lumped mass ( $31 \mathrm{~kg}$ ) has been put on the central part to represent a valve that is an ordinary component found in such equipment. The main geometrical characteristics of the pipe are given in Fig. 4.

The mechanical properties of the constitutive materials (concrete and steel) of the RC specimen have been determined according to the current practice in the nuclear industry [36]. As far as concrete is concerned of which the maximal size of aggregates is about $8 \mathrm{~mm}$, the mechanical properties have been measured at 28 days and just before carrying out the seismic tests (samples were taken on each casting concrete during the construction stage; one can observe a certain discrepancy on the results). They are gathered in Tables 1 and 2 for the concrete and the steel respectively.

\subsubsection{Instrumentation arrangement}

The instrumentation arrangement defined within the framework of the SMART 2013 joint project is similar to the one defined within the framework of the SMART 2008 joint project regarding the measurement channels dedicated to the RC specimen. However, the feedback from the SMART 2008 experimental campaign has clearly pointed out the importance of accurately monitoring the boundary conditions of the whole structural system (RC specimen and shaking table). Therefore, the main improvements were to consider additional sensors at junctions between the shaking table and the actuators. Eight actuators (four in the horizontal directions and four in the vertical direction) were monitored in order to record displacement and acceleration time histories during the whole experimental campaign. Knowledge of this data means that it is possible to accurately control the boundary conditions which are of primary importance when dealing with numerical simulation of the dynamic behavior of such a complex structural system. The pipe has also been monitored so that this component can be studied separately from the rest of the RC specimen. Accelerometers in the three directions have been put at the pipe-ends to monitor the seismic loading and also on the central valve to capture its global dynamic response. Approximately 200 measurement channels were devoted to the monitoring of the structural system, including boundary conditions, and several steel strain gauges. The measurement channels were divided as follows: 75 accelerometers dedicated to the structure, 55 low-velocity-displacement-transducers, 35 strain gauges, 15 specific low-velocitydisplacement-transducers to monitor of interface between the foundation and the shaking table upper plate, 10 diagonal sensors fixed on the little shearwall and 10 accelerometers dedicated to the pipeline. Both acceleration and displacement were monitored at the corners of each slab. In addition, acceleration was monitored at the center of each half of the slabs and at the center of the beams. A detailed description of the sensors locations can be found in [39]. A sketch of a part of the instrumentation arrangement is shown in Fig. 5. Moreover, a digital image stereo-correlation technique is set up to monitor the crack pattern evolution of the shear wall \#V04, at the first story, during the tests using two high frequency cameras.

\subsubsection{Seismic loading procedure}

Specific attention has been given to the definition of the seismic loading procedure. The driving idea was to choose a set of highly damaging bi-axial seismic input ground motions considered to be representative of a real seismic scenario. Mainly natural input ground motions were applied to the RC specimen. Considering 


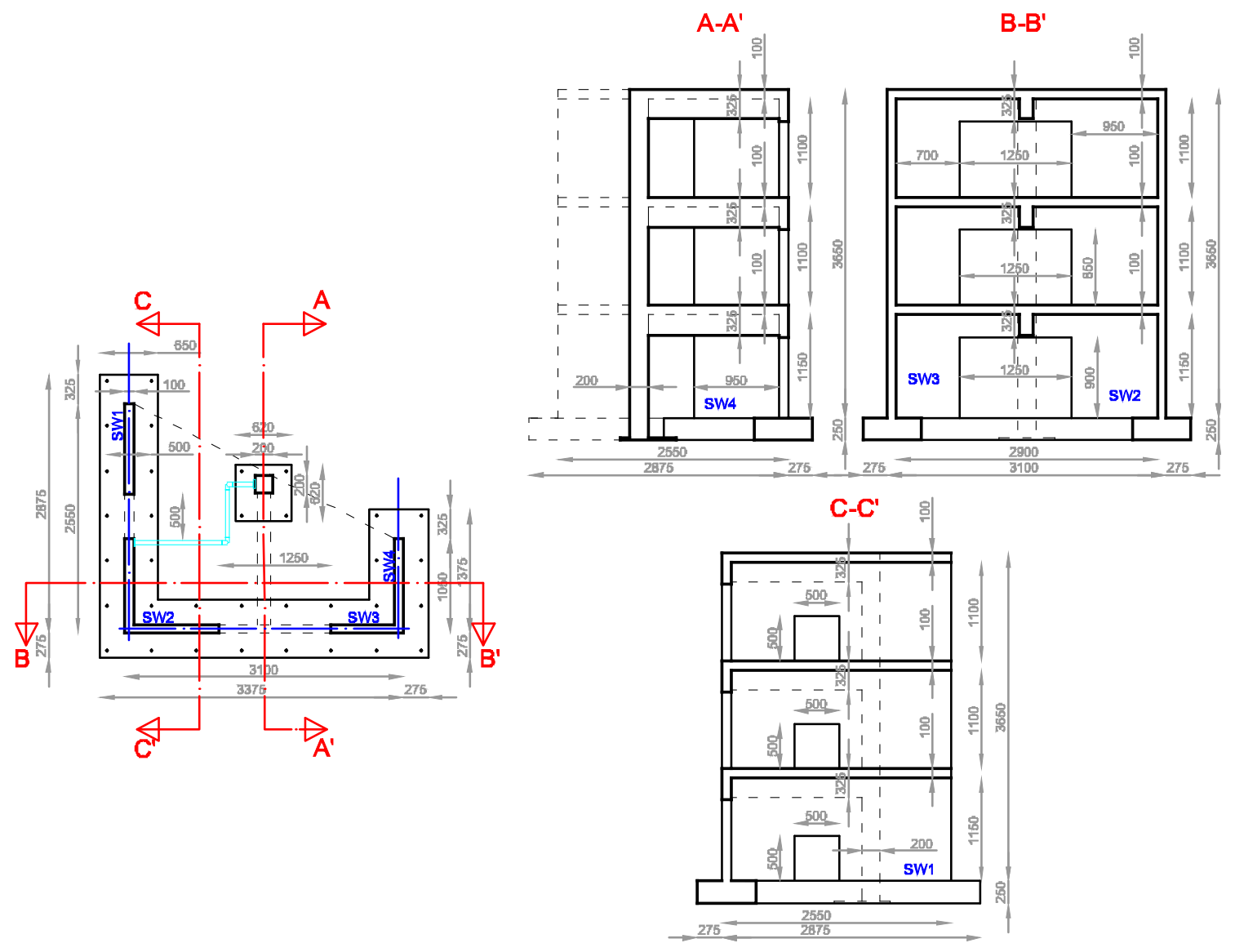

Fig. 3. Formwork drawings of the RC specimen - dimensions in millimeters.

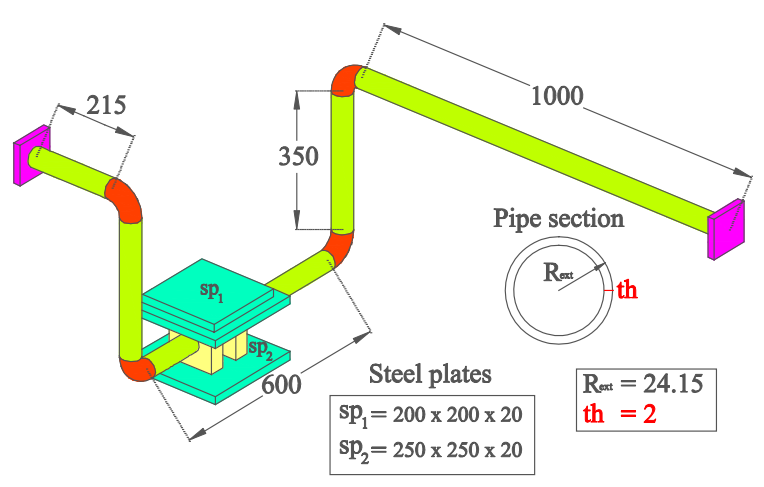

Fig. 4. Geometry of the pipe - dimensions in millimeters. Radius of curvature of the elbows: $57 \mathrm{~mm}$.

the feedback from the SMART 2008 project, the seismic signals have been chosen so that their frequency contents are in accordance with the eigenfrequencies of the RC specimen to ensure their damaging character. In addition, to avoid the unwanted effects of cumulative damage, consensus has been expressed to reduce the number of intermediate seismic tests. The seismic loading is composed of three seismic test sequences. In the test sequence \#1, a synthetic seismic signal corresponding to the seismic demand at the design stage is considered. In the test sequence \#2, the main shock of the Northridge earthquake that occurred in California, USA, in 1994 [40] is considered (Magnitude 6.7) and, in the test sequence \#3, the first aftershock of the same earthquake is considered (Magnitude 5.2.). In the test sequences \#2 and \#3, natural seismic signals extracted from the PEER NGA database [41] at the same monitoring station Tarzana Cedar Hill ( $7 \mathrm{~km}$ from the epicenter) have been selected. Both the time history and the 5\% damping response spectra of the nominal signals are shown in Fig. 6. The eigenfrequency shifts (EFS) measured during the SMART 2008 experimental campaign were taken into account to choose these input ground motions. In this way, input ground motions were chosen so that their frequency content is in accordance with the resonance frequencies of the RC specimen in order to ensure their damaging character. To ensure a satisfactory realization of the seismic input ground motion by means of the shaking table, each test sequence has been split into several seismic runs. Each run aims to apply a given percentage of the nominal seismic signal to the $\mathrm{RC}$ specimen. In order to avoid unwanted effect due to cumulative damage from one run to another, a limited number of intermediate runs has been considered. The full seismic test procedure is described in Table 3. Low level random signals with a PGA in both horizontal directions between 0.05 and $0.1 \mathrm{~g}$ were also applied between each seismic run in order to monitor the evolution of the modal properties of the RC specimen. In addition, similar signals were applied to the specimen from runs \#1 to \#6 in order to get the shaking table properly set up.

\subsection{Description of the numerical model}

The structural system, composed of the RC specimen and the shaking table, has been modeled by means of finite elements based on specific kinematic assumptions in order to avoid unwanted computational time and to process as usual according to engineering practice. The shear walls, the slabs and the central beams have been discretized by multi layered shell finite elements. Five layers have been considered for the concrete and four for the steel. The 
Table 1

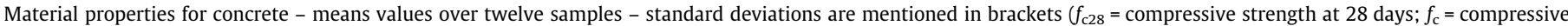

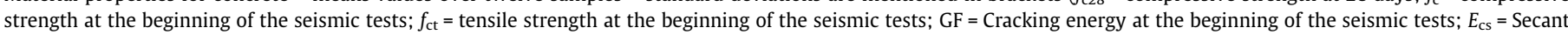
Young's modulus at the beginning of the seismic tests; $v=$ Poisson's ratio at the beginning of the seismic tests).

\begin{tabular}{|c|c|c|c|c|c|c|}
\hline Structural component & $f_{\mathrm{c} 28}(\mathrm{MPa})$ & $f_{\mathrm{c}}(\mathrm{MPa})$ & $f_{\mathrm{ct}}(\mathrm{MPa})$ & $\mathrm{GF}\left(\mathrm{J} \mathrm{m}^{-2}\right)$ & $E_{\mathrm{cs}}(\mathrm{GPa})$ & $v$ \\
\hline Foundation & $35.2(3.1)$ & $43.3(1.2)$ & $3.5(0.2)$ & $135.7(16.8)$ & 25.4 & 0.17 \\
\hline $\begin{array}{l}\text { Shear wall and column } \\
1 \text { st level }\end{array}$ & $45(3.3)$ & $41.7(2.5)$ & $3.1(0.1)$ & $136.0(21.4)$ & 28.7 & 0.19 \\
\hline $\begin{array}{l}\text { Slab and beam } \\
1 \text { st level }\end{array}$ & $38.1(0.9)$ & $41.1(0.7)$ & $3.3(0.3)$ & $133.6(5.3)$ & 28.2 & 0.18 \\
\hline $\begin{array}{l}\text { Shear wall and column } \\
\text { 2nd level }\end{array}$ & $35.3(0.5)$ & $35.5(0.7)$ & $2.7(0.2)$ & $132.2(11)$ & 25.7 & 0.19 \\
\hline $\begin{array}{l}\text { Slab and beam } \\
\text { 2nd level }\end{array}$ & $38.9(0.4)$ & $36.8(2.1)$ & $3.3(0.1)$ & $113.9(16.3)$ & 24.7 & 0.17 \\
\hline $\begin{array}{l}\text { Shear wall and column } \\
\text { 3rd level }\end{array}$ & $51.4(0.3)$ & $46.6(3)$ & $4.0(0.2)$ & $123.2(9.8)$ & 29.5 & 0.18 \\
\hline $\begin{array}{l}\text { Slab and beam } \\
\text { 3rd level }\end{array}$ & $39.2(1.2)$ & $37.8(1.2)$ & $3.4(0.04)$ & $135.4(4.4)$ & 24.4 & 0.18 \\
\hline
\end{tabular}

Table 2

Material properties for steel rebars - means values over three samples.

\begin{tabular}{|c|c|c|c|c|c|}
\hline Steel diameter (mm) & Young's modulus (GPa) & Yield strength (MPa) & $\begin{array}{l}\text { Ratio between the ultimate } \\
\text { strength and the yield strength }\end{array}$ & $\begin{array}{l}\text { Strain corresponding to } \\
\text { the ultimate strength (\%) }\end{array}$ & Type of steel \\
\hline 10 & 202.4 & 500 & 1.141 & 8.83 & Ribbed \\
\hline 8 & 204.7 & 505 & 1.121 & 10.92 & Ribbed \\
\hline 6 & 207.4 & 528 & 1.100 & 6.93 & Ribbed \\
\hline 4 & 202. & 665 & 1.062 & 3.00 & Smooth \\
\hline 3 & 177.5 & 629 & 1.076 & 2.00 & Smooth \\
\hline
\end{tabular}

values of the eccentricity and the thickness parameters have been determined according to the formwork and reinforcement drawings. The foundation has been discretized by solid finite elements. The column has been represented as a vertical beam; well-known Timoshenko multi-fiber beam finite elements have been considered. The pipe has been discretized by means of a modified version of Euler-Bernoulli beam elements devoted to the modeling of pipes which are available in CAST3M [42]. In order to ensure an accurate control of the boundary conditions, the shaking table has also been included in the structural model. It is composed only of shell finite elements, since the shaking table can be seen as an assembly of shells and plates. A detailed description of the shaking table model can be found in [43]. The overall mesh is composed of 13,178 finite elements and 10,779 nodes. The meshes of the RC specimen and the shaking table are shown in Fig. $7 a$ and $b$ respectively.

The accuracy of the numerical results is highly dependent on the choice of the constitutive laws since they can be used to describe the energy dissipations and stiffness degradation due to the loading. Concrete has been modeled using a constitutive law

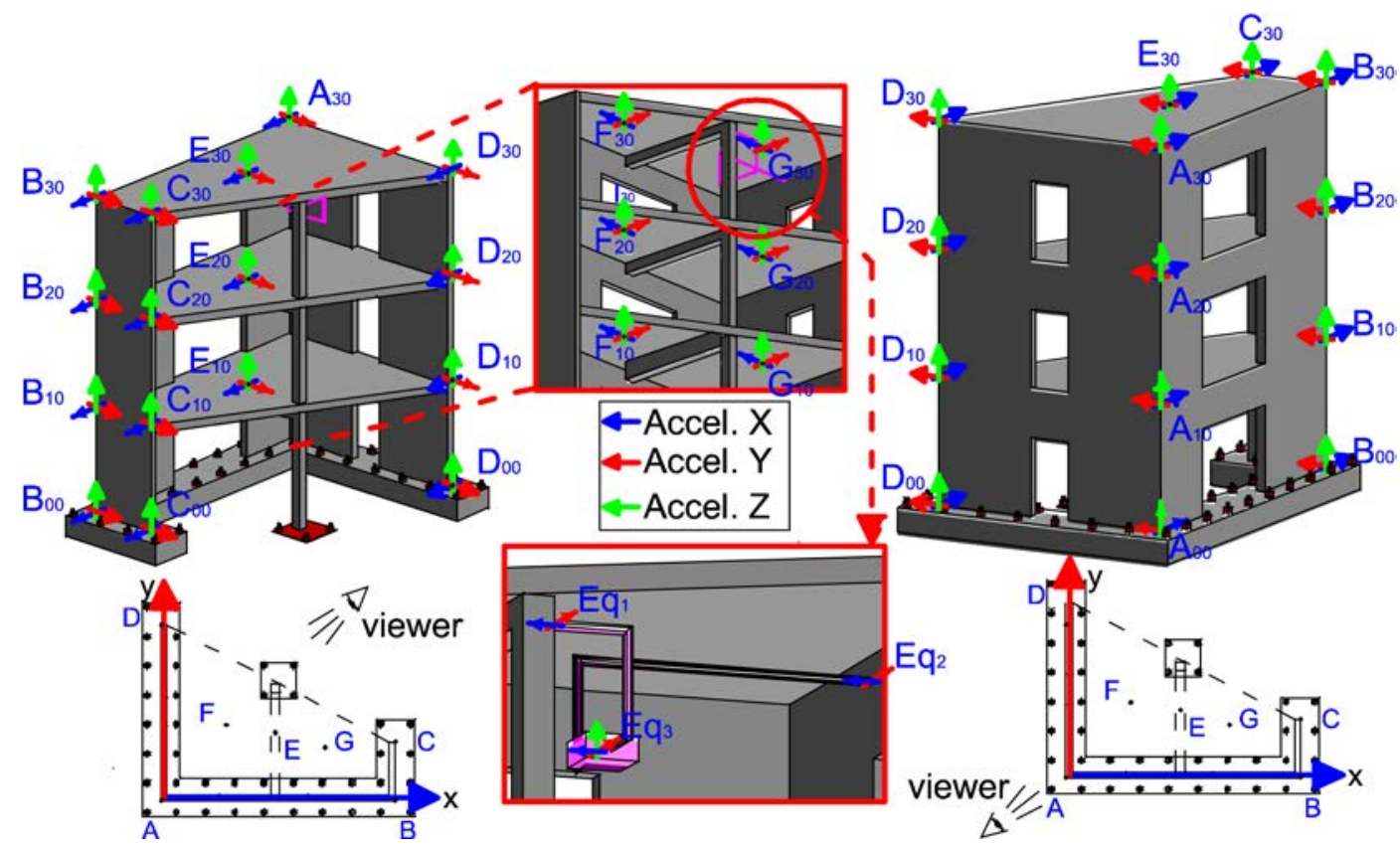

Fig. 5. Main measurement points 


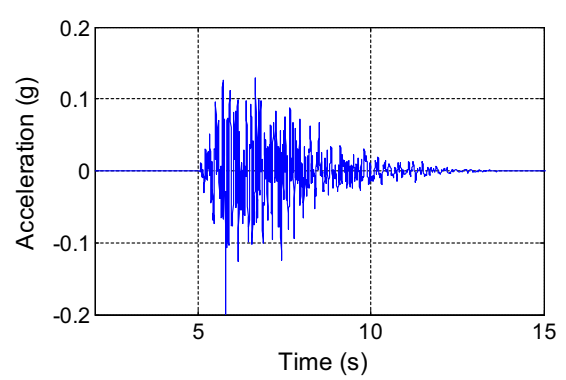

(a) Acceleration time history - Design signal $-\mathrm{X}$ direction.

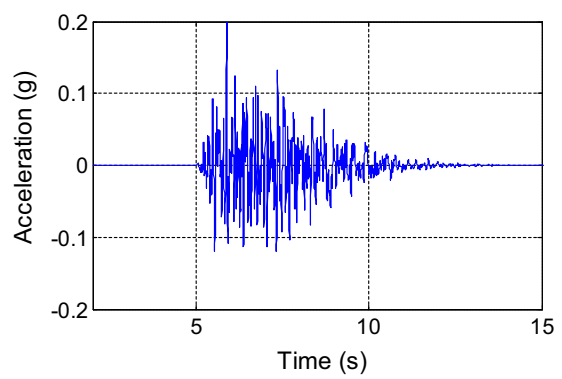

(c) Acceleration time history - Design signal - Y direction.

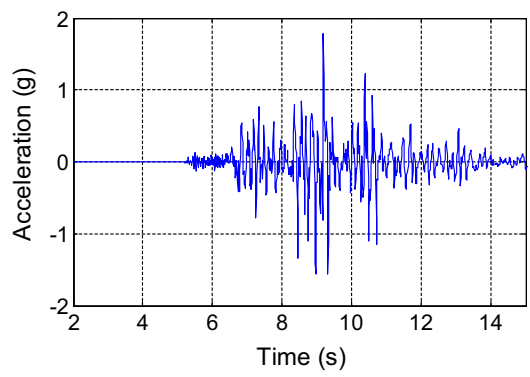

(e) Acceleration time history - Northridge mainshock $-\mathrm{X}$ direction

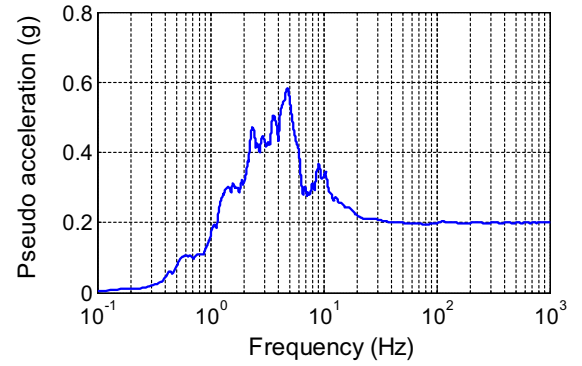

(b) Response spectrum - Design signal - $\mathrm{X}$ direction.

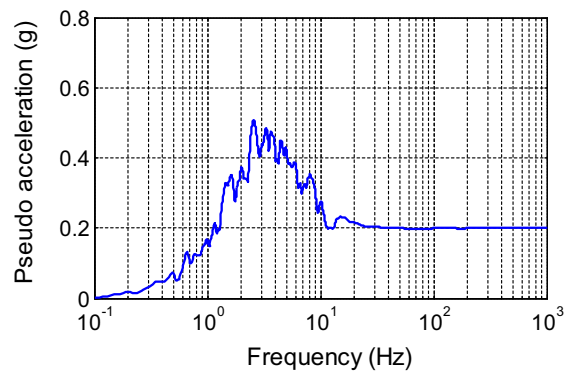

(d) Response spectrum - Design signal - Y direction.

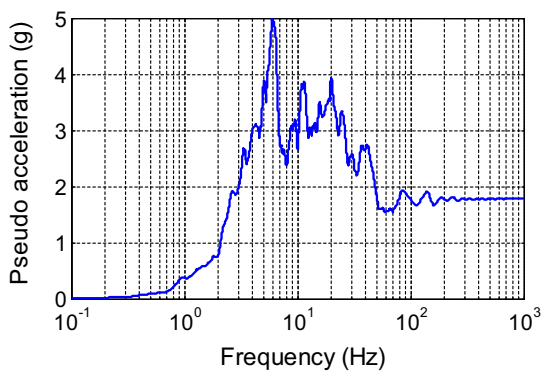

(f) Response spectrum - Northridge mainshock -

$\mathrm{X}$ direction.

Fig. 6. Nominal input ground motions considered in SMART 2013 experimental program.

of continuum damage mechanics. It is a simplified version of the 3D constitutive law developed by [44], which is adapted to the case of plate formulation in order to fulfill the plane stress condition. The main effects taken into account are the asymmetry between the softening behaviors in tension and in compression and the so-called unilateral effect which is crucial when dealing with cyclic loadings. The concrete constitutive law requires the identification of six material parameters: two elastic parameters (Young's modulus and Poisson's ratio), two threshold parameters (tensile and compression strengths) and two softening parameters (cracking energies in tension and in compression). Apart from the cracking energy in compression which was assumed to be equal to 10 times the cracking energy in tension, the whole set of material parameters has been identified from the experimental measurements gathered in Table 1. It is important to notice that the spatial distribution of the concrete material parameters, as identified from the measurements, has been taken into account in the numerical model by applying the measured values at each floor. The steel reinforcing bars have been modeled by the well-known Menegotto-Pinto constitutive law [45]. Similarly to the concrete material parameters, the ones related to the Menegotto-Pinto constitutive law have been identified from the experimental measurement shown in Table 2. The steel/concrete interface is assumed to be perfect: a full load transfer between the steel and the surrounding concrete is allowed. The way of controlling the boundary conditions is essential to making an accurate description of the dynamic behavior of a specimen during a shaking table test. Within the framework of the SMART 2013 experimental campaign, specific attention has been paid to monitoring the displacement and acceleration time histories at the junction between the actuators and the shaking table. In order to accurately take account the complex kinematics of the dynamic system, seismic loading has been applied by prescribing the displacement time histories at each connection point between the eight actuators and the shaking table. The nonlinear problem has been solved in the absolute reference frame. Once the problem solved, the acceleration time histories monitored at the bottom of the foundation were compared to the ones computed in order to check the correct application of the seismic loading. In order to represent the contribution of the dissipated energy not taken into account by the constitutive laws and to avoid numerical issues mainly related to strain localization, a viscous damping model has been included in the numerical model. The well-known Rayleigh viscous damping model has been considered [46], leading to a viscous damping matrix proportional to both the initial stiffness (without updating) and the mass matrix. The parameters of the Rayleigh's damping model have been computed 


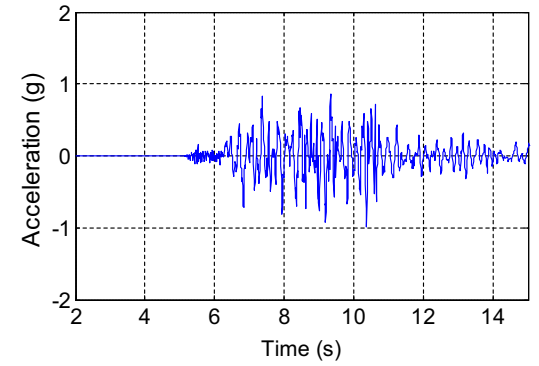

(g) Acceleration time history - Northridge mainshock - Y direction.

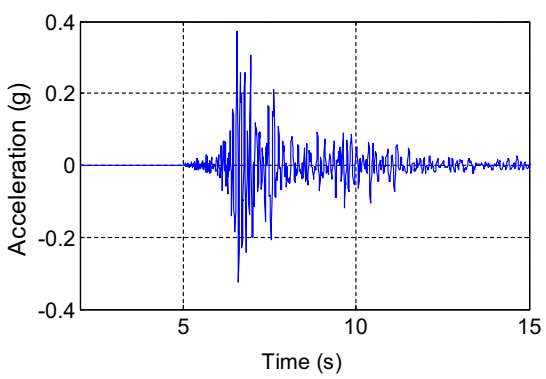

(i) Acceleration time history - Northridge aftershock $-\mathrm{X}$ direction

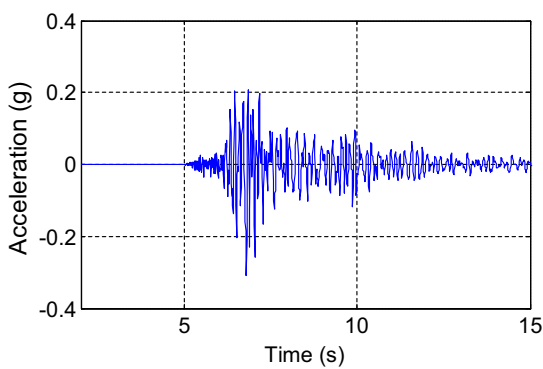

(k) Acceleration time history - Northridge aftershock $-\mathrm{Y}$ direction.

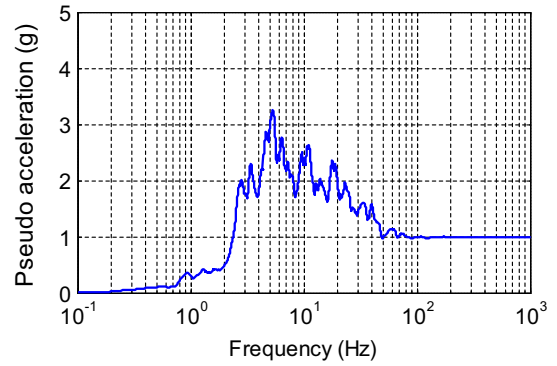

(h) Response spectrum - Northridge mainshock $\mathrm{Y}$ direction.

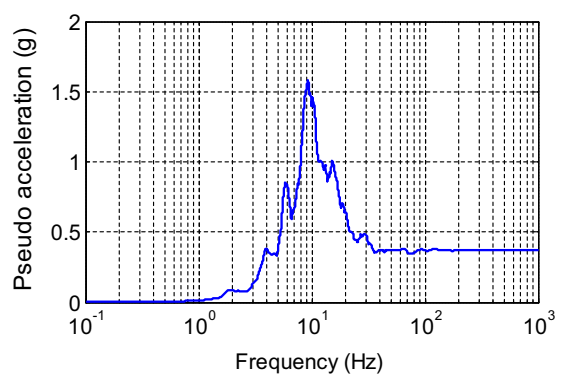

(j) Response spectrum - Northridge aftershock $\mathrm{X}$ direction.

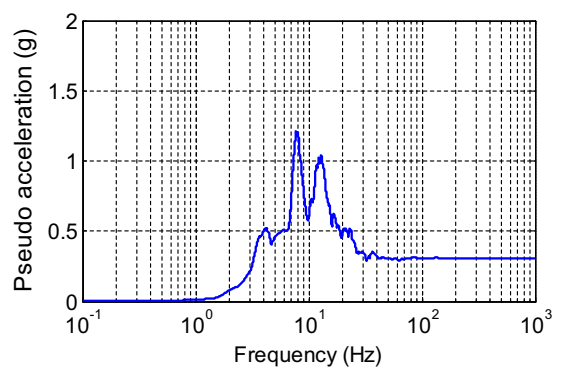

(1) Response spectrum - Northridge aftershock -

$\mathrm{Y}$ direction.

Fig. 6 (continued)

Table 3

Seismic loading procedure $-\mathrm{DL}=$ Design Level; MS = Main Shock; AS = Aftershock - percentages are computed, for a given test sequence, as the ratio between the PGA of a run and nominal PGA.

\begin{tabular}{|c|c|c|c|c|c|c|}
\hline Test sequence number & $\begin{array}{l}\text { Run } \\
\text { number }\end{array}$ & $\begin{array}{l}\text { Target PGA in } \\
X \text { direction }(\mathrm{g})\end{array}$ & $\begin{array}{l}\text { Target PGA in } \\
Y \text { direction }(\mathrm{g}) \\
\end{array}$ & $\begin{array}{l}\text { Realized PGA in } \\
X \text { direction }(\mathrm{g})\end{array}$ & $\begin{array}{l}\text { Realized PGA in } \\
Y \text { direction }(\mathrm{g})\end{array}$ & Brief description \\
\hline Test sequence \#1: DL & $\begin{array}{l}7 \\
9\end{array}$ & $\begin{array}{l}0.10 \\
0.20\end{array}$ & $\begin{array}{l}0.10 \\
0.20\end{array}$ & $\begin{array}{l}0.13 \\
0.22\end{array}$ & $\begin{array}{l}0.14 \\
0.23\end{array}$ & $\begin{array}{l}\text { DL }-50 \% \\
D L-100 \%\end{array}$ \\
\hline
\end{tabular}

from the two first initial eigenfrequencies of the RC mock-up in order to obtain a damping ratio equal to $2 \%$, which is an ordinary value when nonlinear constitutive laws are considered $[35,36,47]$. The nonlinear dynamic problem has been solved with the finite element software CAST3M [42], using a Newmark's time integration scheme the numerical parameters of which have been set to ensure unconditional stability (constant average acceleration). In addition, the time step is equal to $9.76 \cdot 10^{-4} \mathrm{~s}$ and the convergence criterion (based on the norm of the residue vector) is equal to $10^{-4}$.

\subsection{Modal identification of the initial state}

The initial dynamic properties (eigenfrequencies, modeshapes and modal damping ratios) have been characterized from the experimental measurements in order to assess the predictive 


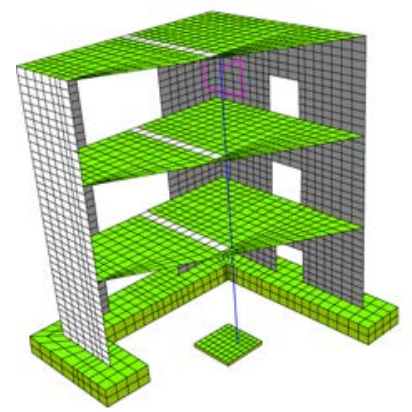

(a) RC specimen and pipe (in pink)

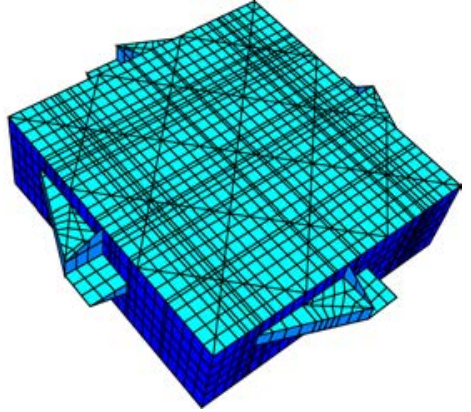

(b) Shaking table

Fig. 7. Finite element mesh.

capability of the numerical model regarding the modal properties. Before applying the seismic loadings to the dynamic system, it has been subjected to a biaxial random signal. The outputs have fed an operational modal analysis technique [48] used to estimate the modal properties of the system. In order to check the relevancy of the numerical model presented in Section 2.2, a numerical modal analysis has been carried out. The numerical modeshapes and the corresponding eigenfrequencies are compared with the results from the measurements in Fig. 8 and Table 4 respectively. Results similar to the ones obtained within the framework of the SMART 2008 experimental campaign can be observed. The RC specimen exhibits a first modeshape bending around $Y$ direction occurs, a second modeshape bending around $X$ direction occurs and a third modeshape in which torsional effect are predominant occurs. In order to quantify the correlation between the experimental and numerical modeshapes, the modal assurance criterion (MAC) matrix has been computed considering the first, second and third modes. A graphical representation of the matrix is shown in Fig. 9. The diagonal terms are almost equal to 1 and the nondiagonal one are close to 0 . This result shows the good concordance between the numerical and the experimental modeshapes. The results in Table 4 show that the numerical model properly describes the first eigenfrequency but a gap between the experimental and the numerical eigenfrequencies appears for the second and the third modes. Indeed, the modal properties (eigenfrequencies, modal damping ratios and modeshapes) are experimentally identified by the operational modal analysis realized on the basis of the structural responses measured during the initial white noise excitation. This approach provides estimations of the modal properties of the dynamic system composed of the structure, the shaking table and the hydraulic system used to supply the actuators with the necessary power. However, the numerical modal analysis aims to solve an eigenvalue problem which does not take the hydraulic system into account. Therefore, both analyses provide estimations of modal properties that are not exactly related to the same structural system. This point might explain the differences observed between the numerical and the experimental values of the eigenfrequencies. However, it is important to notice that no adjustment of the material parameters has been made; the numerical eigenfrequencies and modeshapes are obtained by inputting the measured material parameters.

\section{Structural responses}

\subsection{Overall damage pattern}

From run \#7 to run \#11, no significant cracking has been observed on the RC specimen, only diffuse cracking close to the geometric singularities has been observed. The main localized cracks began initiating during the run \#13. The main areas that cracked were the shear wall \#4, the first slab and the junction between the foundation and the shear wall \#4. From run \#17 to run \#19, the aforementioned parts of the RC specimen become more and more cracked. In particular, shear cracking pattern could be observed in the shear wall \#4, as shown in Fig. 10a and b. The failure of the RC specimen occurs during run \#19 with the propagation of crack at the junction between the foundation and the shear wall \#4. Due to the presence of this crack, an important uplift of the shear wall \#4 has been observed during run \#19. During this uplift, the steel reinforcing bars had yielded. It is also believed that sliding at the steel/concrete interface occurred. When the RC specimen went down, the concrete crushed suddenly, as shown in Fig. 10c.

Due to the ability of the numerical model used, damage areas after each seismic run could be obtained. The isovalues of the damage variable in the outer layer, ranging from 0 (virgin material - blue ${ }^{1}$ ) to 1 (failed material - red), are shown in Fig. 11. Comparing the cracking pattern experimentally observed after run \#17 (see Fig. 10a) with the damage pattern shown in Fig. 11a, one can notice that the first level of the shear wall \#4 is the most degraded. Indeed, the numerical model could not represent the cracks in a localized way but only in a smooth way. This is a classical drawback of continuum damage based models. Looking at the damage pattern obtained after run \#19, one can observe that both the degradation of the slabs and the localized cracks close to the openings have been captured in a satisfactory way. Though, the result is qualitative in nature, it is in good concordance with the cracking pattern shown in Fig. 10b. Due to the fact that no specific feature can be used to deal with contact included in the model, the concrete crushing shown in Fig. 10 could not at all be observed.

\subsection{Acceleration responses}

In this section, the acceleration responses of the RC specimen are presented in order to quantify two aspects of its dynamic behavior: (i) the evolution of the floor response spectra (FRS) in both horizontal directions and (ii) the variations of the zero period acceleration (ZPA) as a function of the story. Only the results obtained at point D (see Fig. 5), which is the most excited point, are considered in this section. The results are presented for each seismic test sequence; some peculiarities can be observed according to the seismic test sequence considered. The FRS, computed at point $\mathrm{D}$, located at the third floor in both horizontal directions, is shown in Figs. 12-14 for each seismic test sequence respectively. The experimental results are compared with the ones obtained

\footnotetext{
${ }^{1}$ For interpretation of color in Figs. 11 and 18, the reader is referred to the web version of this article.
} 


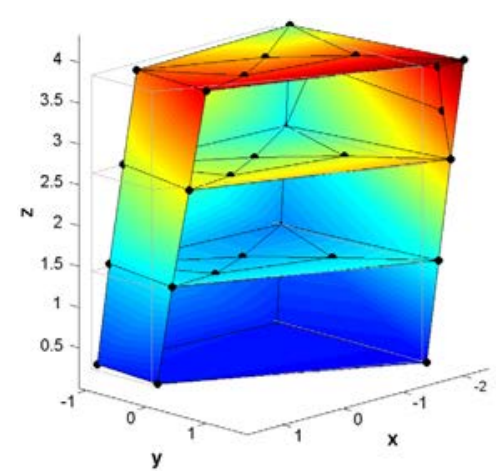

(a) $1^{\text {st }}$ modeshape experimental

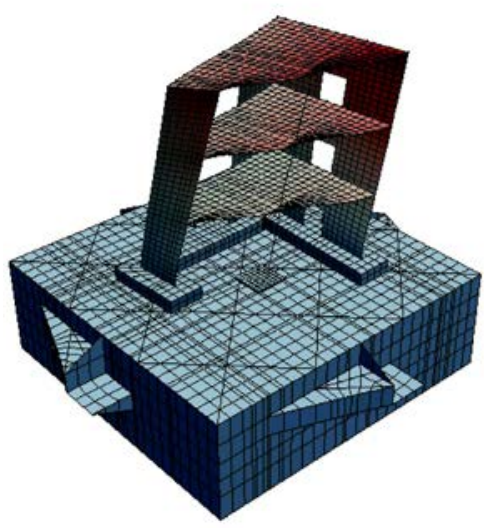

(d) $1^{\text {st }}$ modeshape - numerical

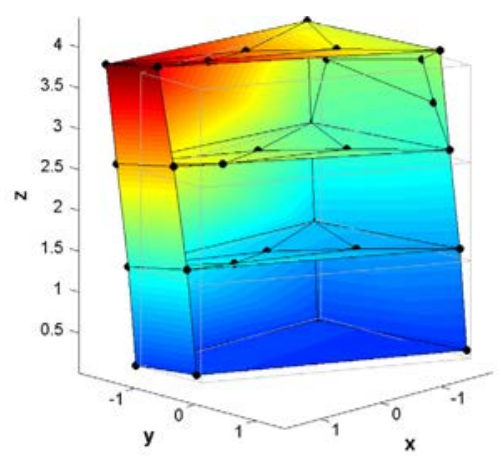

(b) $2^{\text {nd }}$ modeshape experimental

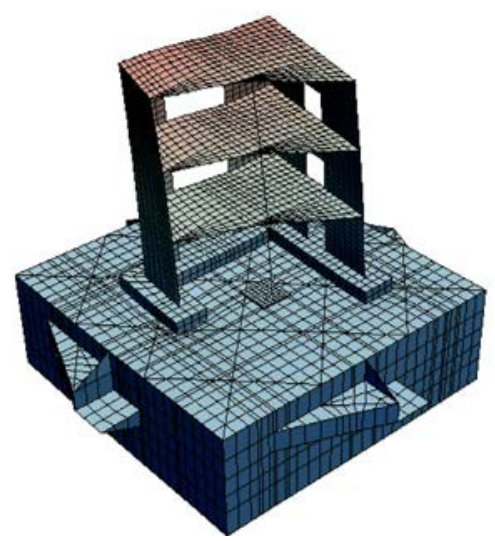

(e) $2^{\text {nd }}$ modeshape - numerical

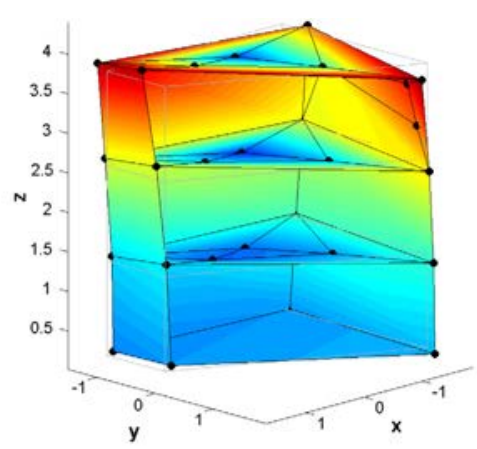

(c) $3^{\text {rd }}$ modeshape experimental

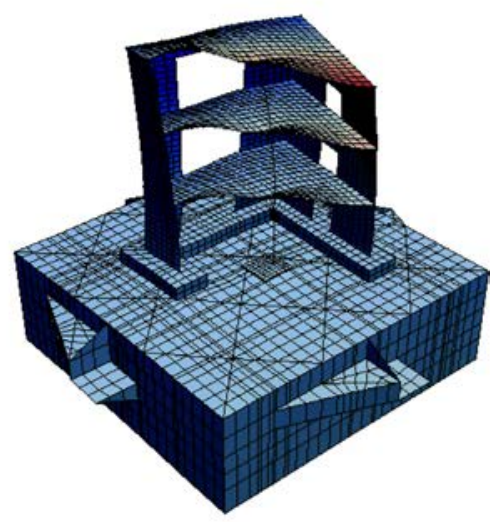

(f) $3^{\text {rd }}$ modeshape - numerical

Fig. 8. Comparison between the experimental and the numerical modeshapes.

Table 4

Initial eigenfrequencies and modal damping ratios - experimental/numerical comparison.

\begin{tabular}{lllll}
\hline \multirow{2}{*}{ Mode number } & \multicolumn{2}{l}{ Eigenfrequency $(\mathrm{Hz})$} & \multirow{2}{*}{$\begin{array}{l}\text { Modal damping } \\
\text { ratio (\%) }\end{array}$} \\
\cline { 2 - 4 } & Experimental & Numerical & Error $(\%)$ & \\
\hline 1 & 6.28 & 6.79 & +8.1 & 2.6 \\
2 & 7.86 & 10.19 & +30.2 & 4.2 \\
3 & 16.5 & 21.87 & +30.5 & 5.5 \\
\hline
\end{tabular}

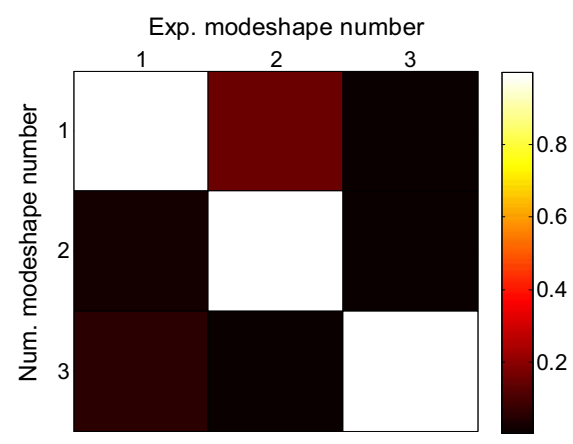

Fig. 9. Graphical representation of the MAC matrix computed on the basis of the 1 st, 2nd and 3rd numerical and experimental modes - the color scale ranges from black (correlation coefficient equal to 0 ) to white (correlation coefficient equal to 1 ). (For interpretation of the references to color in this figure legend, the reader is referred to the web version of this article.) by the nonlinear numerical model presented in Section 2. Regarding the seismic sequence \#1, a satisfactory concordance can be observed in Fig. 12. In case of run \#7, the numerical model clearly succeeds in describing the dynamic response of the RC specimen in both directions. Moreover, in case of run \#9, similar observations can be made. In case of the $Y$ direction, one can notice that the numerical model overestimates the pseudo acceleration around $10 \mathrm{~Hz}$. This gap may be due to the fact that the second eigenfrequency is overestimated. In other words, this may mean that the stiffness distribution, in particular, of the one related to the shear wall \#4, which is the structural component that controls the overall response of the specimen, may not be well represented. To improve the modeling results, it might have been useful to monitor the forces in the shear wall \#4 to better represent the torsional stiffness but this strategy is far from being straightforward.

Regarding the results related to the seismic test sequence \#2, two main observations can be made. First, the experimental results show a frequency decrease of the first peak from $6.5 \mathrm{~Hz}$ to $3.5 \mathrm{~Hz}$ over the whole test sequence. However, the numerical results show that the model is unable to capture this effect. The gap is increasing with the intensity of the seismic run. This means that the model does not release a sufficient amount of energy due to the nonlinear processes which occur during the seismic loading. Second, a strong asymmetry in terms of amplitude can be observed if one focuses on the $X$ direction or on the $Y$ direction. This is in agreement with the fact that the Northridge mainshock signal is strongly asymmetric, as it can be observed in Fig. $6 \mathrm{f}$ and h. Furthermore, the asymmetric character of the structural response is 


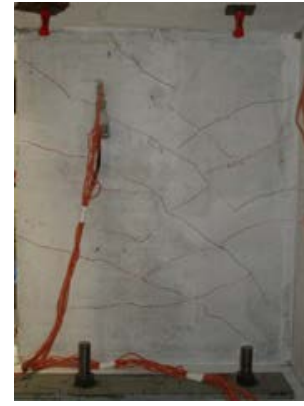

(a) Cracking in the shear wall \#4 after run \#17.

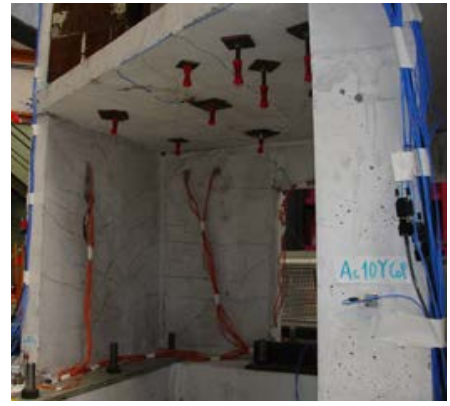

(b) Cracking at the $1^{\text {st }}$ level after run $\# 19$.

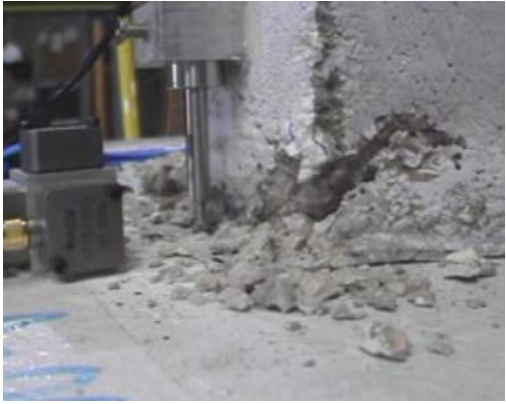

(c) Crushing of the concrete at the junction between the shear wall \#4 and the foundation during run \#19.

Fig. 10. Experimental observations of the degradation process up to the failure/up to failure.

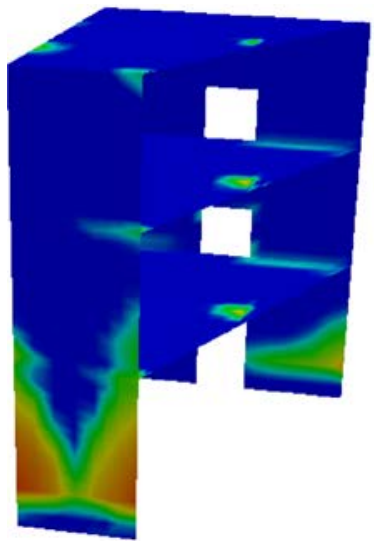

(a) After run \#17.

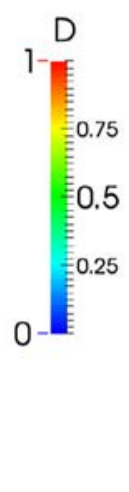

(b) After run \#19.

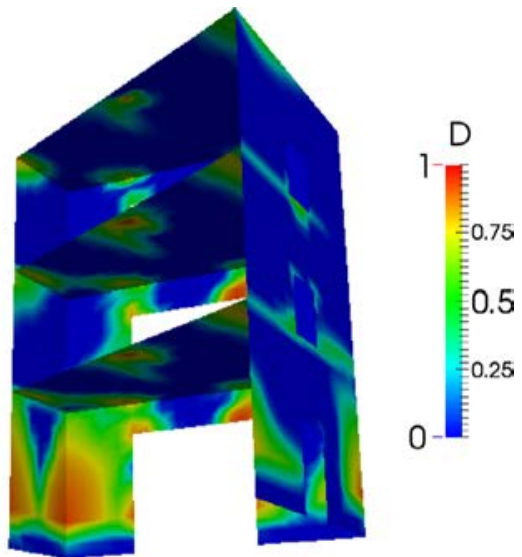

Fig. 11. Damage pattern.

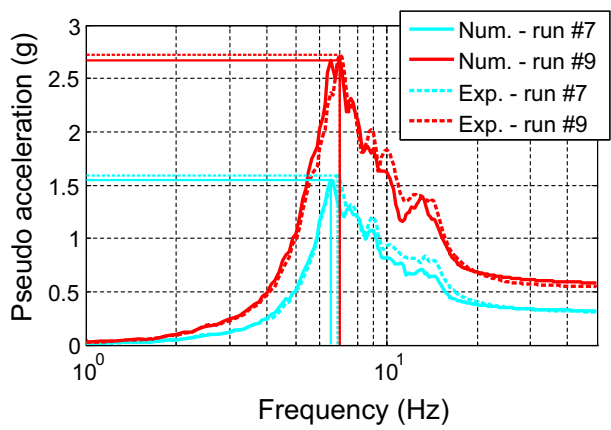

(a) $\mathrm{X}$ direction

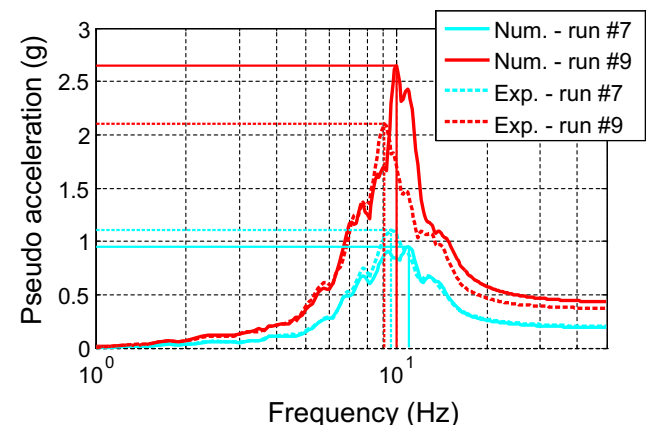

(b) Y direction

Fig. 12. Experimental/numerical comparison of the FRS computed at point D located at on the third floor - seismic sequence \#1 - design signal.

stressed by the degradation of the shear wall \#4. Indeed, Fig. 10c highlights concrete crushing at the end of run \#19. The shear wall \#4 was only linked with the foundation by the steel reinforcement bars. In other words, the stiffness in the $Y$ direction was highly reduced, leading to a decrease of the structural response in this direction. The ability of the numerical model to describe the asymmetry of the structural responses can be pointed out. This means the numerical model can describe the torsion movement of the RC specimen.
When it comes to the seismic test sequence \#3, the results are in agreement with those obtained in the test sequence \#2. Indeed, because the stiffness degradation was not described accurately in the test sequence \#2, significant differences can be observed in terms of peak frequencies specifically in the case of the $X$ direction. In addition, in the case of the $X$ direction, the fact that the peak frequencies do not change for both runs of the test sequence \#3 is well captured by the numerical model whereas the corresponding amplitudes in terms of pseudo-acceleration are not. Consequently, 


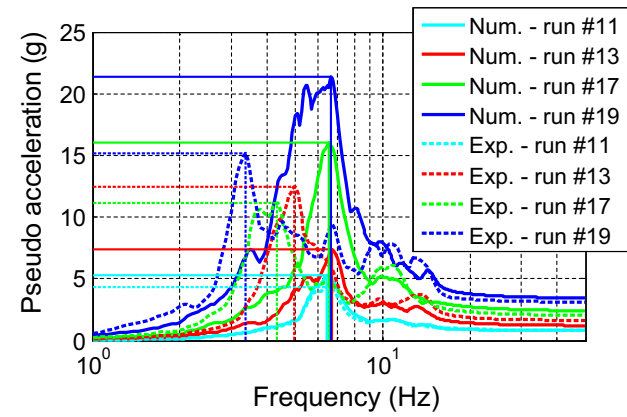

(a) $\mathrm{X}$ direction

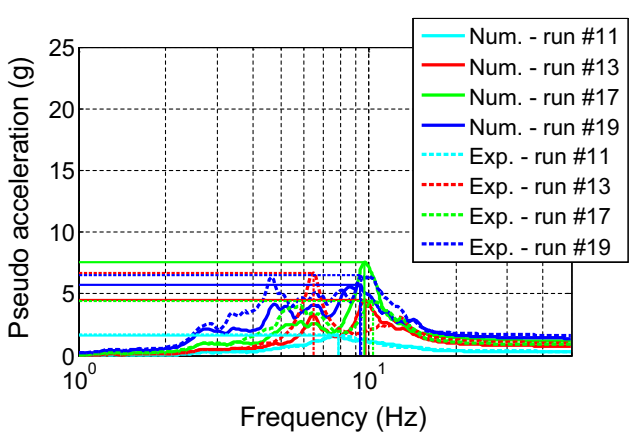

(b) Y direction

Fig. 13. Experimental/numerical comparison of the FRS computed at point D located at on the third floor - seismic sequence \#2 - Northridge mainshock.

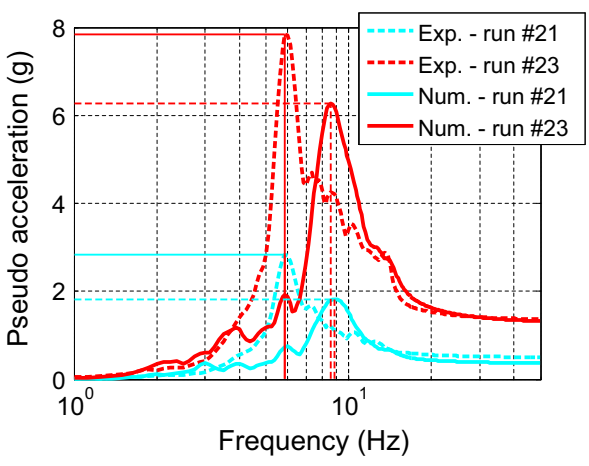

(a) $\mathrm{X}$ direction

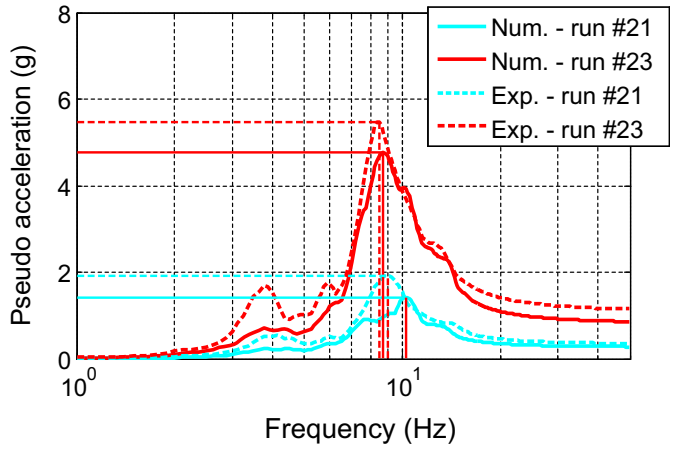

(b) $\mathrm{Y}$ direction

Fig. 14. Experimental/numerical comparison of the FRS computed at point D located at on the third floor - seismic sequence \#3 - Northridge aftershock.

the model properly predicted the fact that no additional damage appeared during the test sequence \#3. The gap between the numerical and the experimental results observed on the amplitudes of the pseudo-accelerations means that the model is overdamped. In the case of the $Y$ direction, the agreement between the experimental results and the numerical ones is right.

As an indicator of the dynamic amplification in the high frequency range, the ratio of the ZPA at point D over the PGA of the input ground motion has been considered. The experimental measurements have been compared with the numerical results. The results are shown in Figs. 15-17 for each seismic test sequence considered respectively. Regarding the seismic test sequence \#1, one can notice in Fig. 15a and b that the amplification experimentally measured is well described by the numerical model for each floor and for both horizontal directions. In addition, the amplification increases almost linearly in a monotonic way in the $X$ direction. This trend does not appear in the $Y$ direction since the amplification increases and then decreases. This effect is properly captured by the numerical model and may be explained by both the strong asymmetry of RC specimen and the apparition of some diffuse cracks at the design level which contribute to the energy dissipation.

Regarding the seismic test sequence \#2, the results for both directions are shown in Fig. 16a and b. Apart from the run \#13 with PGAs in the $X$ direction equal to $0.45 \mathrm{~g}$ and in the $Y$ direction equal to $0.28 \mathrm{~g}$, one can observe that the amplification ratio is properly described. The gap observed represents the inability of the numerical model to describe the dynamic amplification during the run \#13. Indeed, a major crack at the shear wall/foundation interface appeared during this seismic run. However, the amplification is mainly governed by damage or, in other words, by the damping properties of the system. Consequently, for this loading case, the gap may be explained by the fact the dynamic system is overdamped. Two sources of damping were considered: the viscous damping with a ratio equal to $2 \%$ and a contribution from the hysteretic scheme included in the concrete constitutive law. The latter contribution might not have been optimally described due to the lack of experimental data available from material tests. If additional information related to the hysteretic scheme of the constitutive concrete had been available from the experimental characterization tests, the viscous damping ratio might have been adjusted in consequence in order to underdamp the system. In this way, the correspondence between the experimental and the numerical values would have been better. A linear increase of the amplification ratio with respect to the altitude (floor level) is observed from the experimental measurements. This trend is properly captured by the numerical model.

The evolution of the amplification ratio during the seismic test sequence \#3 is shown in Fig. 17 in both horizontal directions. A satisfactory agreement between the experimental measurement and the numerical results can be pointed out in both directions.

\subsection{Displacement responses}

In this section, the displacement responses of the RC specimen are analyzed through experimental/numerical comparisons. Among the various quantities that could be discussed, the choice was made to focus the analysis on the overall displacements of the third floor. The objectives were to study the capability of the numerical model to describe torsional effects and, consequently, to assess the relevancy of an inter-story drift (ISD) based on criterion to quantify damage in the case of such a complex structure. The trajectories of the four corners of the slab located at the third floor, determined from the experimental measurements, are com- 


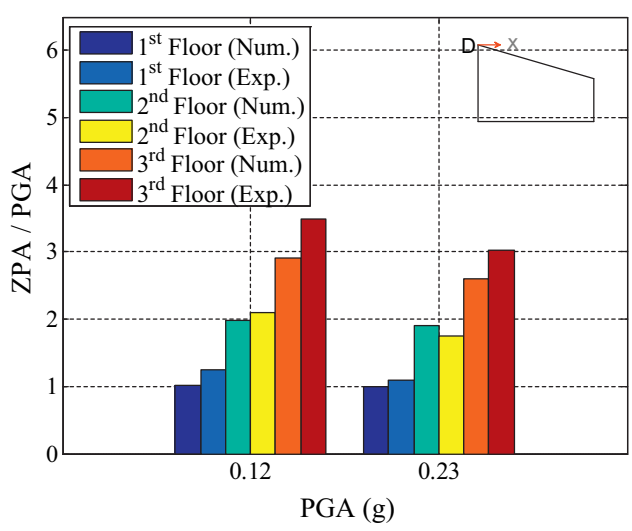

(a) $\mathrm{X}$ direction at point $\mathrm{D}$.

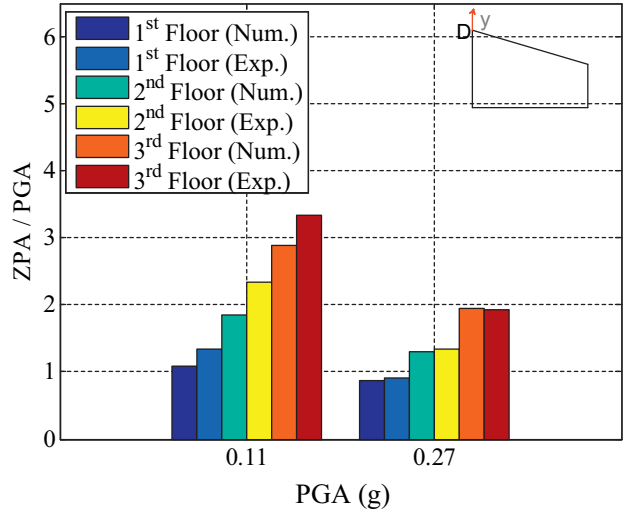

(b) $\mathrm{Y}$ direction at point $\mathrm{D}$.

Fig. 15. Numerical/experimental comparisons of the ratio ZPA/PGA - design seismic signal.

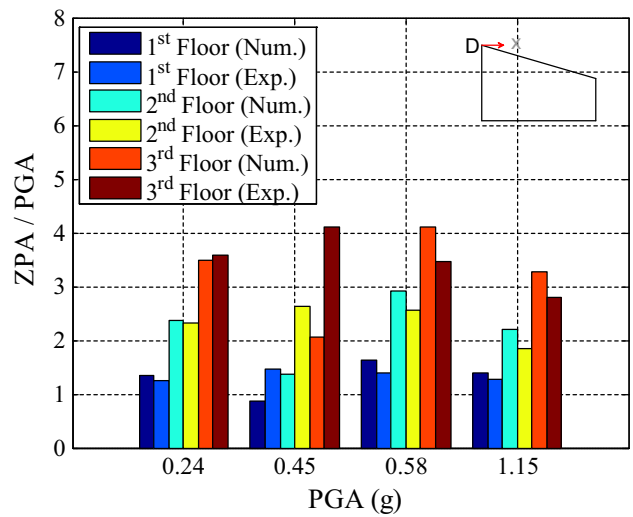

(a) $\mathrm{X}$ direction at point $\mathrm{D}$.

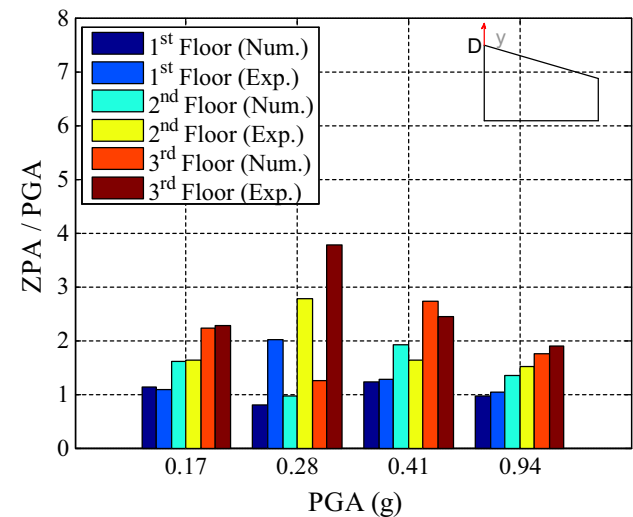

(b) Y direction at point $\mathrm{D}$.

Fig. 16. Numerical/experimental comparisons of the ratio ZPA/PGA - Northridge mainshock.

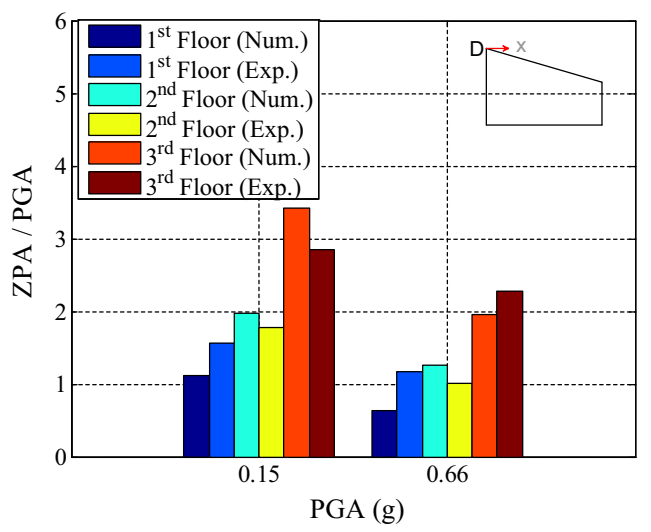

(a) $\mathrm{X}$ direction at point $\mathrm{D}$.

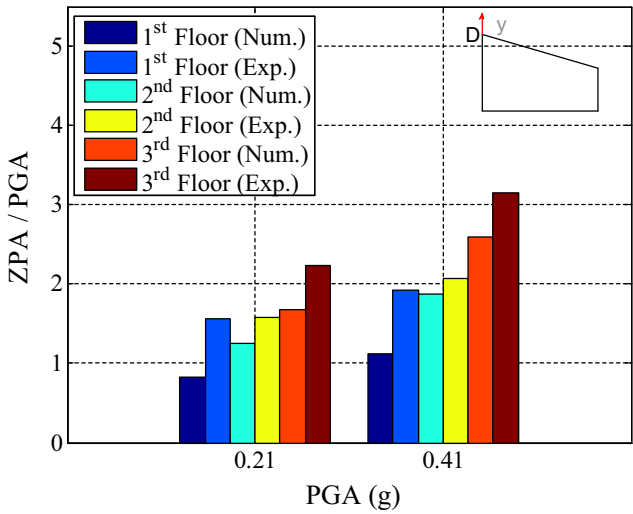

(b) $\mathrm{Y}$ direction at point $\mathrm{D}$.

Fig. 17. Numerical/experimental comparisons of the ratio ZPA/PGA - Northridge aftershock.

pared with those computed by the developed numerical model. Only the three nominal (with a loading factor equal to 1 ) seismic runs are considered, that is to say, runs \#9, \#19 and \#23. The results are shown in Fig. 18a, b and c respectively. Regarding the run $\# 9$, a good agreement between the experimental measurements and the numerical results can be observed. Indeed, we notice that both the amplitude of the displacements and the principal direction (depicted by a green line) are properly described by the numerical model leading to the conclusion that the torsional effects are properly described. Regarding run \#19, we observe a modification of the overall kinematics. In particular, the displacements in the $X$ direction become preponderant at point $\mathrm{D}$. The amplitude of the experimental displacement is underestimated whereas the principal direction is properly captured. Finally, regarding the run $\# 23$, we observe that the amplitude of the displacements is properly described whereas the principal direction 


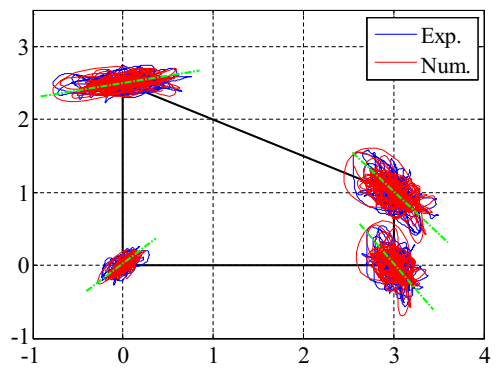

(a) Run \#9 - design signal - scale factor equal to 250 .

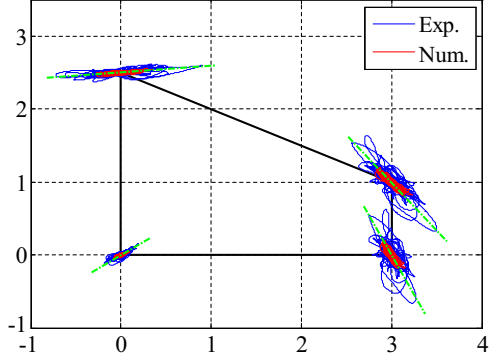

(b) Run \#19 - Northridge mainshock - scale factor equal to 30 .

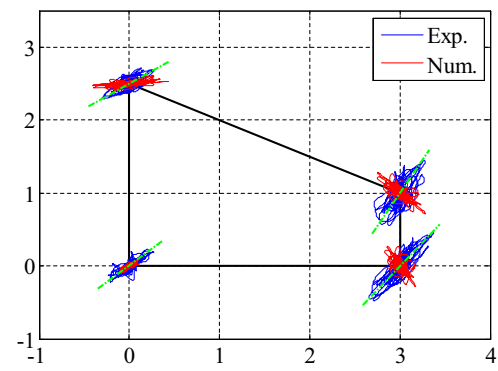

(c) Run \#23 - Northridge aftershock - scale factor equal to 250 .

Fig. 18. Overall displacement response of the third floor.

suffers from a lack of accuracy. The last observations may be explained by the fact that the numerical model was not able to accurately capture the degradation that occurred in the area of the shear wall \#4 and in particular, the transversal crack that appeared at the interface between the foundation and this shear wall.

\subsection{Pipeline responses}

The acceleration responses of the pipeline model are exposed and discussed in this section. The dynamic behavior of the pipeline model was monitored in three observation points, as shown in Fig. 5. Because the observation points named Eq1 and Eq3 were located close to the column and the shearwall respectively, the responses monitored at these locations do not represent the intrinsic behavior of the pipeline but they quantify the behavior of the RC structure. However, the observation point named Eq3 was located on the lumped mass fixed at the middle of the pipeline. Therefore, the responses monitored at this location characterize the behavior of the pipeline model. They are presented in Fig. 19 in the $X$ and $Y$ directions for the three nominal seismic levels of each seismic test sequence. The experimental/numerical comparisons show that the numerical model underestimates the experimental measurements in terms of pseudo-acceleration. This is particularly true in the $Y$ direction. This issue can be explained by the fact that the damping was not properly described at the level of the equipment. Indeed, since the pipeline was not pressurized during the experimental campaign, the damping is particularly low and is not consistent with respect to the one considered in case of the RC structure. A better description of the damping related to the pipeline might have helped to better describe its dynamic behavior. Another point of interest is related to the very low value of damping identified experimentally. Indeed, the half band power method led to a value of the damping ratio equal $0.25 \%$, which is particularly low. Therefore, this value should be chosen carefully when designing or assessing the seismic behavior of pipelines. For instance, it could be interesting to iden- tify the dissipation phenomena localized in pipe supports that are known to be the main contributions to the dissipation process related to this kind of secondary structures.

\section{Structural robustness assessments}

\subsection{Driving ideas}

In this section, a robustness assessment analysis of the RC specimen is presented. The objective is to assess the capability of the RC specimen to withstand extreme earthquake loading scenarios, considering that it was designed according to the engineering practices applicable in the French nuclear industry for a PGA equal to $0.2 \mathrm{~g}$. To reach this objective, the structural degradation state is assumed to be represented by a damage indicator. Because the findings of such analysis are naturally dependent on the choice of the criteria, two indicators have been considered. The evolutions of these damage indicators versus a seismic intensity measure are analyzed in the following sections. They are compared with specific thresholds expressed either in terms of ISD or EFS. The first is relevant to represent the ductile failure, even if it is questionable when considering torsional motions, whereas the second is appropriate to study RC buildings involving stiffness degradation in their failure process and is useful when dealing with equipment seismic assessment analysis. The values of the thresholds are presented in Table 5 and are used to define three damage states which can be qualified as "light", "controlled" and "extended", as usually proposed in the literature. The evolution of the damage indicators are analyzed with respect to the loading factor $\lambda^{i}$ which is defined for a given seismic sequence as follows:

$\lambda^{i}=\frac{\mathrm{PGA}^{i}}{\mathrm{PGA}^{\mathrm{Ref}}}$

where PGA ${ }^{\text {Ref }}$ stands for the maximum PGA of the last seismic run of a given seismic sequence, while $P G A^{i}$ is the PGA of the seismic input considered. It is worth noticing that the last seismic run of a given 


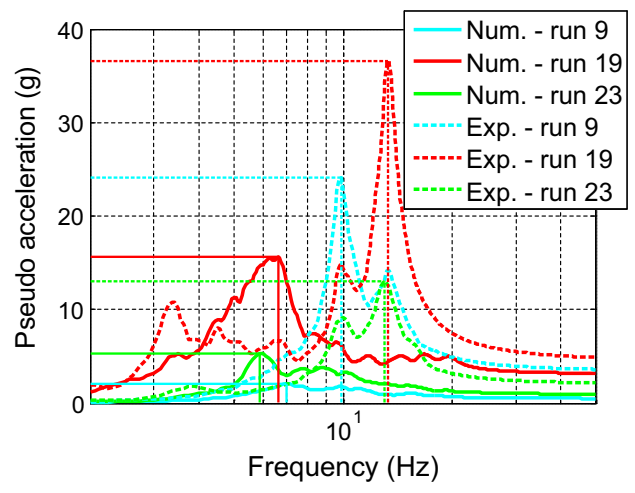

(a) $\mathrm{X}$ direction

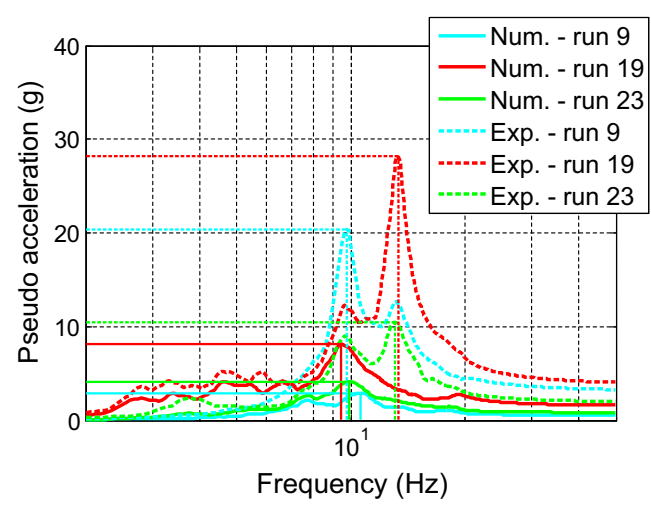

(b) Y direction

Fig. 19. Experimental/numerical comparison of the response spectra computed at point Eq3 located on the lumped mass fixed on the pipeline model.

Table 5

Prescribed values of the thresholds for the failure functions ( $h=$ story height).

\begin{tabular}{lll}
\hline Damage level & $\begin{array}{l}\text { Inter-story drift } \\
\text { threshold }(\mathrm{mm})\end{array}$ & $\begin{array}{l}\text { Peak-frequency } \\
\text { shift threshold (\%) }\end{array}$ \\
\hline Light & $\frac{h}{400}$ & 15 \\
Controlled & $\frac{h}{200}$ & 30 \\
Extended & $\frac{h}{100}$ & 50 \\
& & \\
\hline
\end{tabular}

seismic sequence has a loading factor equal to 1 . In this way, it is possible to assess the robustness of the RC specimen for each seismic test sequence considered in the experimental campaign.

\subsection{Inter-story drift}

The results expressed in terms of ISD are shown in Fig. 20 for both horizontal directions and for each seismic sequence. Regarding the seismic sequence \#1, the agreement between the experimental measurements and the numerical results is right. It is worth noticing that even if the design level is considered, small nonlinearities such as microcracks or small cracks appeared. Therefore, the numerical model is able to accurately describe the structural responses of the RC specimen when it is subjected to a seismic loading close to the design level. Regarding the seismic sequence \#2, the results highly depend on the direction. In case of the $X$ direction in which the maximum ISD was recorded, the experimental measurements are underestimated by the numerical computations by a factor higher than 2 . In other words, the numerical model failed to accurately describe the displacement response of the RC specimen because of the difficulty of reproducing the major transversal crack which appeared during the test sequence $\# 2$. In addition, the "extended damage" threshold is clearly exceeded for a PGA almost equal to $2.0 \mathrm{~g}$. According to the definition of damage levels, a PGA 4 or 5 times higher than the design PGA is needed to reach an "extended damage" state. In that sense, the RC specimen can be qualified as being structurally robust. Furthermore, the question of the definition of the thresholds expressed in terms of ISD may also be put. Indeed, the qualification of the damage state based upon the ISD estimation is not representative of the cracking pattern experimentally observed. On the contrary, in the case of the $Y$ direction, the agreement between the experimental and the numerical results is better. In particular, it appears that the light damage level is just exceeded. Furthermore, the strong asymmetry observed in Fig. $18 \mathrm{c}$ and $\mathrm{d}$ is consistent with the results shown in Fig. 18b. Lastly, regarding the seismic test sequence \#3, the agreement between the experimental measurements and the numerical results is satisfactory in both horizontal directions. It is also interesting to notice that the "light damage" level is not exceeded. This observation is in agreement with the fact that no additional damage was monitored during the seismic sequence \#3. Indeed, the seismic response of the RC specimen was fully conditioned by the cracks and, in particular, the major one, which appeared during the seismic test sequence \#2.

\subsection{Eigenfrequency shift}

In this section, the damage indicator is expressed in terms of first and second EFS. This indicator differs from the previous one because it accounts for the overall dissipation and stiffness degradation of the RC specimen. In other words, it is less local than the ISD. The evolutions of both the first and the second EFS with respect to the loading factor, for each seismic test sequence, are reported in Fig. 21. The experimental values were determined by analyzing the structural responses of the RC specimen under random excitations between each seismic run [49]. The numerical eigenfrequencies after each seismic run were computed by carrying out a new modal analysis based on the secant stiffness matrix of the structure. As mentioned in Section 2.2, the constitutive law used to describe the cyclic behavior of concrete is based on isotropic continuum damage mechanics. From the damage variable field available after each seismic run, it is possible to estimate the damage elastic properties and therefore to compute the secant stiffness matrix. More precisely, the secant stiffness matrix can be easily computed numerically from the secant Hooke matrix as follows:

$K=\sum_{e} \int_{\Omega_{e}} B_{e}^{t} \tilde{C}_{e} B_{e} d \Omega$

where $\sum(\cdot)$ stands for the assembly operator, $e$ the number of finite elements, $\Omega_{e}, B_{e}$ the gradient matrix of the shape functions and $\tilde{C}_{e}=(1-d) C_{e}$ the elemental secant Hooke matrix. This strategy allows damage to be taken into account when computing the eigenfrequencies and the modeshapes. Regarding the results presented in Fig. 21, the shifts are expressed relative to the undamaged first or second eigenfrequencies computed before the RC specimen was subjected to the seismic loading. Regarding the seismic test sequence \#1, the "light damage" threshold is never exceeded. In addition, we observe a low shift in the case of the first eigenfrequency and almost no shift in the case of the second eigenfrequency. This shows that the RC specimen exhibited only small nonlinearities during the design signal. Regarding the seismic test sequence \#2, the numerical results underestimate the experimental values. This observation is in agreement with the fact that the 


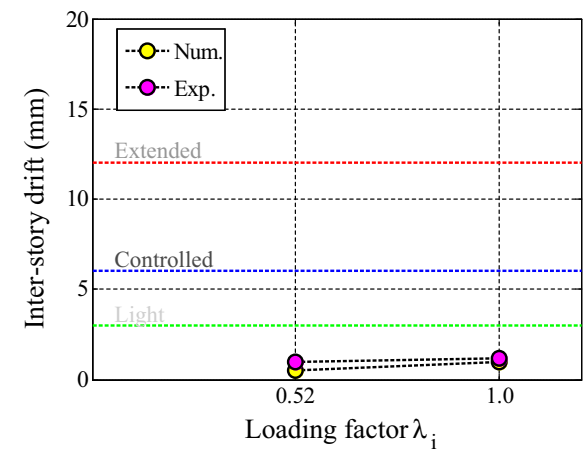

(a) X direction - seismic sequence \#1.

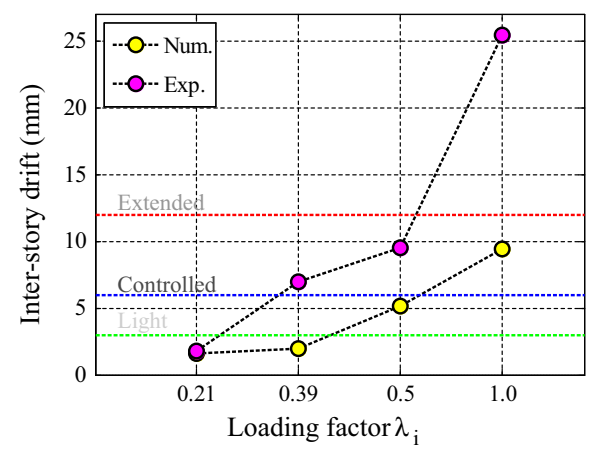

(c) $\mathrm{X}$ direction - seismic sequence \#2.

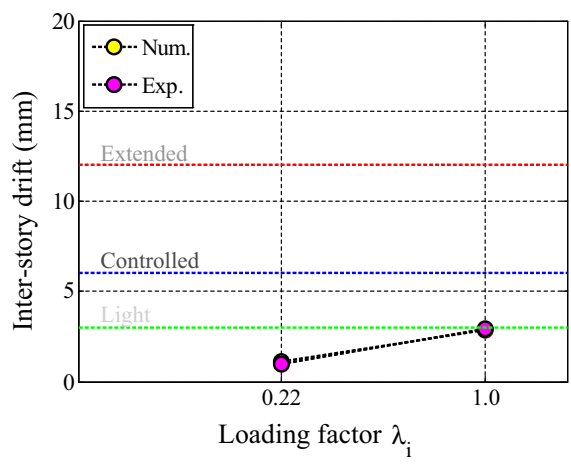

(e) $\mathrm{X}$ direction - seismic sequence \#3.

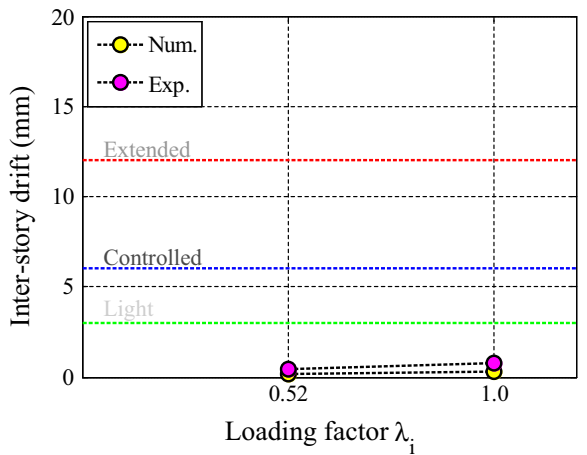

(b) Y direction - seismic sequence \#1.

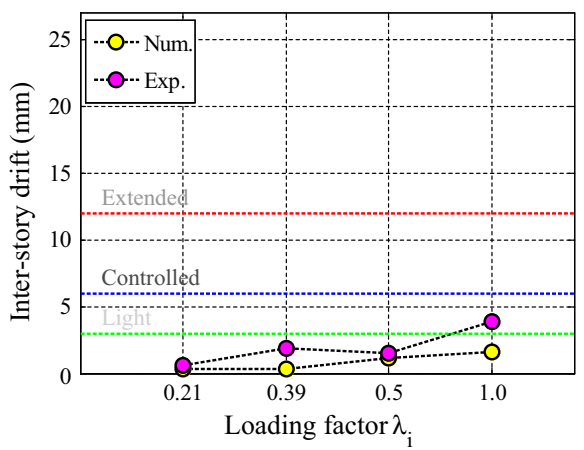

(d) Y direction - seismic sequence \#2.

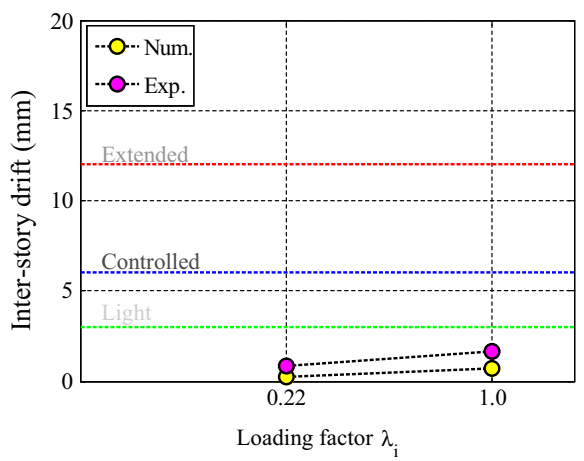

(f) Y direction - seismic sequence \#3.

Fig. 20. Experimental/numerical comparisons of the inter-story drifts for each seismic sequence.

numerical model failed to accurately describe the stiffness degradation due to cracking in the case of very strong loading. However, it is worth noticing that the extended damage threshold is exceeded for a loading factor equal to 1 to a lower extent than in the case of the ISD indicator. In other words, the EFS indicator leads to the conclusion that the RC specimen is less damaged than when the ISD indicator is used. This observation is consistent with the one made in the previous section in that the question of the damage thresholds used to quantify the structural state needs to be addressed. Regarding the seismic test sequence \#3, the EFS remain almost constant and this corroborates the fact that no additional damage was created during this sequence.

\section{Conclusions and outlooks}

This paper presents and discusses the results from shaking table tests carried out on a RC specimen within the framework of the SMART 2013 CEA-EDF-IAEA joint research project. The 1/4 scale RC specimen under study is part of an electrical building designed according to the guidelines and regulations applicable in the French nuclear industry. The seismic loading was composed of three seismic test sequences: the design synthetic signal, the Northridge earthquake mainshock and the Northridge earthquake aftershock. Each seismic sequence was stepped into several seismic runs in order to ensure a robust control of the shaking table to reproduce as best possible the targeted signals. It is worth noticing that the whole seismic loading was defined in order to ensure damage of the RC specimen by choosing a frequency content of the loading in agreement with the first natural frequencies of the $\mathrm{RC}$ specimen fixed on the shaking table. For this reason, the seismic scenario considered within the framework of SMART 2013 can be considered as extreme, regarding the design requirements in Europe and specifically in France.

The experimental observations made after the seismic test sequence \#1 revealed that only small nonlinearities occur during this test sequence. This means that even though the PGAs of the 


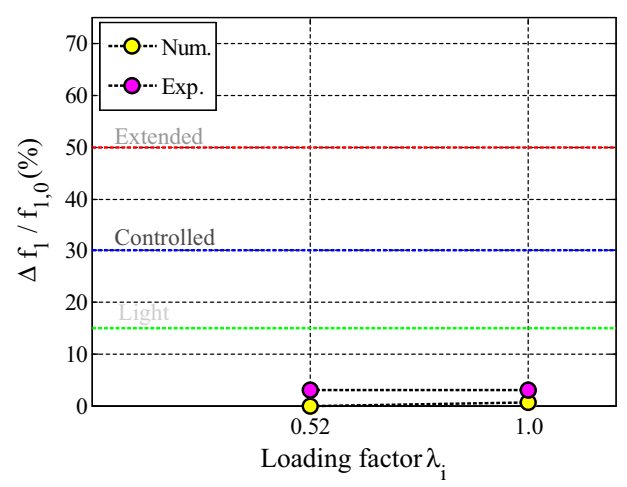

(a) First eigenfrequency - seismic sequence \#1.

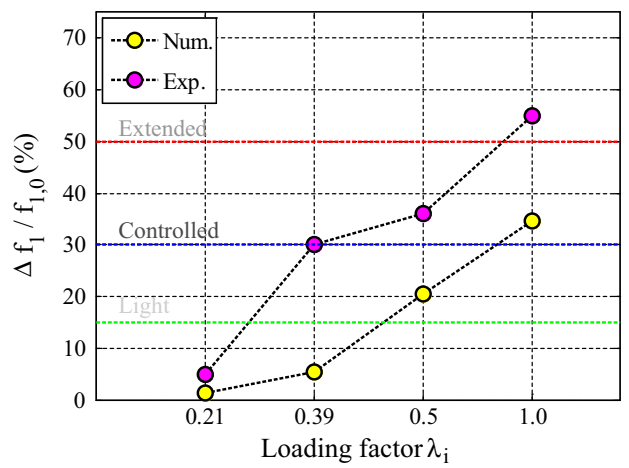

(c) First eigenfrequency - seismic sequence \#2.

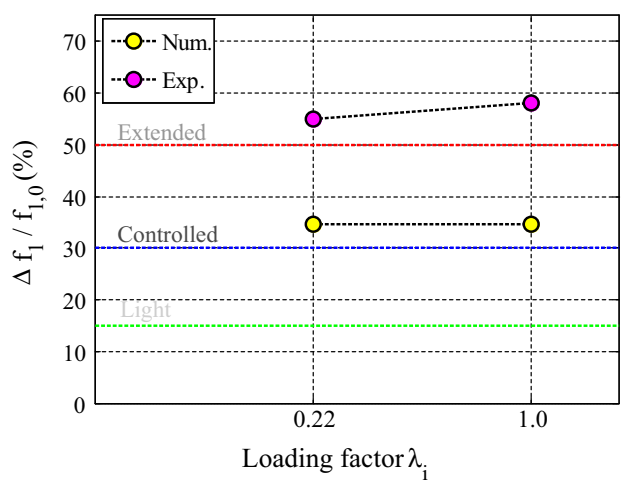

(e) First eigenfrequency - seismic sequence \#3.

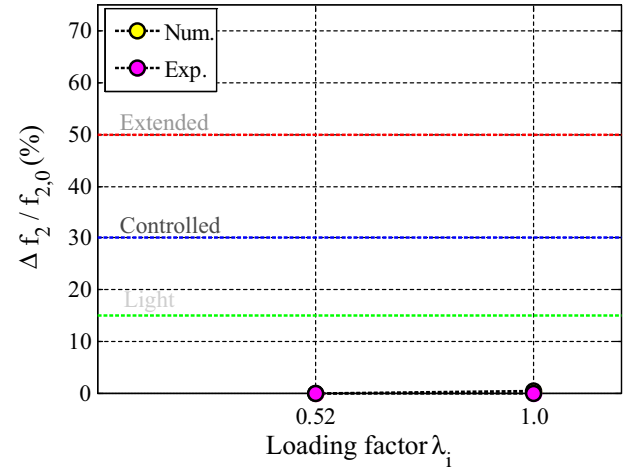

(b) Second eigenfrequency - seismic sequence \#1.

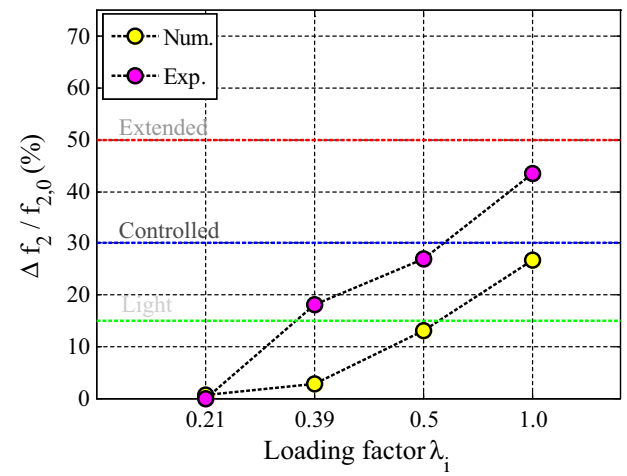

(d) Second eigenfrequency - seismic sequence \#2.

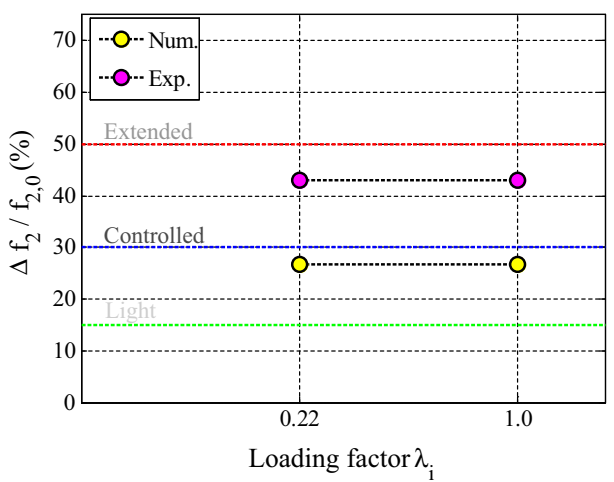

(f) Second eigenfrequency - seismic sequence \#3.

Fig. 21. Experimental/numerical comparisons of the eigenfrequency shifts for each seismic sequence.

seismic input ground motions applied to the RC specimen are lower or equal to the design PGA, the RC specimen no longer actually worked in its linear range. Therefore, suitable nonlinear constitutive models should be implemented to capture this effect in order to meaningfully assess the seismic behavior of the RC specimen. The most important cracks were observed during the seismic test sequence \#2, i.e. going to the mainshock. In particular, a major crack appears at the interface between the foundation and the shortest shear wall. This crack was responsible for most of the stiffness loss of the RC specimen. In addition, this degradation mode is in agreement with the one observed within the framework of the SMART 2008 experimental campaign. Finally, no additional damage was monitored after the seismic test sequence \#3, i.e. dealing with the aftershock. The numerical model was able to accurately predict the seismic behavior of the RC specimen up to run \#17. In case of stronger input ground motions, the stiffness degradation of the model was not sufficient to describe the one observed experimentally.

From the numerical/experimental comparisons extensively detailed in this paper, it can be concluded that the best-estimate nonlinear finite element model did not satisfactorily capture all the features of the structural responses in the case of high input ground motions with PGA higher than 4 or 5 times the design PGA. The amplitude of the FRS was properly described by the numerical model whereas the resonance frequencies were not suitable for all the seismic runs. In particular, the EFS were underesti- 
mated. Regarding the displacement responses, the ISD were underestimated in the $X$ direction whereas they were quite satisfactorily described in the $Y$ direction. This can be explained but by the fact that the structural response of the $\mathrm{RC}$ specimen is becoming more and more directional due to the propagation of damage. Indeed, the major crack at the interface between the foundation and the most shear wall \#4 leads to a strong modification of the kinematics. Regarding the torsional effects, they have been highlighted from the experimental measurements. The analyses of the trajectories of the points located at the four corners of the third floor confirmed that the numerical model underestimated the amplitude of the displacements whereas it properly captured their principal directions.

The last part of this paper was devoted to the assessment of the structural robustness of the RC specimen. Two failure criteria were considered: one expressed in terms of EFS and another expressed in terms of ISD. In connection with the definition of the damage thresholds, three key points should be mentioned. First, it appeared that "extended damage" level was reached at the end of the seismic test sequence \#2 for a PGA equal to 4 or 5 times the design PGA. However, according to the European macroseismic scale updated in 1998 (EMS98) [50], a grade between 2 and 3 could corresponds to the cracking observations reported in this paper. Second, though the EFS were underestimated by the numerical model, the results obtained during the seismic test sequence \#3 confirmed that no additional damage appeared due to the Northridge aftershock. This trend was captured by the numerical model since no evolution of the shift was obtained. Last, the question should be put of the applicability of the ISD indicator in the case of an irregular shear wall based structures designed according to the nuclear engineering practices and the fact that the EFS may be a more suitable indicator in that case should be considered regarding the experimental evidences brought by the SMART 2013 research program. However, the issue of the choice of the damage thresholds used to quantify the damage state of the structure should be thoroughly investigated.

The results reported in this paper contribute to showing the structural robustness of the tested RC specimen. Nevertheless, the numerical/experimental comparisons presented in this paper have confirmed the relevancy of ongoing work on the development of advanced nonlinear models. For instance, the way of describing the dissipated energy by the constitutive materials (concrete and steel) still needs to be improved. Another point of interest is the description of damping. Indeed, further improvements should be made in order to use more physical damping models. One possibility may be to make the viscous damping matrix dependent on a structural damage indicator so as to modify it according to the degradation level reached or, more simply, to localize it in the most dissipative areas.

\section{Acknowledgements}

The authors would like to thank the CEA and EDF for providing the material and financial support required to carry out this work. The work reported in this paper has been also supported by the SEISM Institute (http://www.institut-seism.fr).

\section{References}

[1] Červenka V. Inelastic finite element analysis of reinforced concrete panels under in-plane loads. Doctoral dissertation, University of Colorado; 1979.

[2] Paulay T. Some aspects of shear wall design. Bull NZ Soc Earthq Eng 1972;5(3).

[3] Alexander CM, Heidebrecht AC, Tso WK. Cyclic load tests on shear wall panels In: Proceedings, fifth world conference on earthquake engineering, Rome: 1973. p. 1116-9.

[4] Cardenas AE, Russell HG, Corley WG. Strength of low-rise structural walls, vol 63. ACI Special Publication; 1980.
[5] Paulay T, Priestley MJN, Synge AJ. Ductility in earthquake resisting squat shearwalls. ACI journal proceedings, vol. 79, no. 4. ACI; 1982.

[6] Simeonov B. Experimental investigation of the strength, stiffness and ductility of RC structural walls. In: World conference on earthquake engineering, vol. 6; 1998. p. 387-94.

[7] Endebrock EG, Dove RC, Dunwoody WE. Analysis and tests on small-scale shear walls. FY-82 final report (No. NUREG/CR-4274; LA-10443-MS). Los Alamos National Lab., NM (USA); 1985.

[8] Wiradinata S. Behaviour of squat walls subjected to load reversals. Doctoral dissertation, Department of Civil Engineering, University of Toronto; 1985

[9] Dove RC, Bennett JG, Farrar C, Anderson CA. Seismic category I structures program: final report, FY 1983-84 (No. NUREG/CR-4924; LA-11013-MS). Los Alamos National Lab., NM (USA); 1987.

[10] Lefas ID, Kotsovos MD, Ambraseys NN. Behavior of reinforced concrete structural walls: strength, deformation characteristics, and failure mechanism. ACI Struct J 1990;87(1).

[11] Barda F, Hanson JM, Corley WG. Shear strength of low-rise walls with boundary elements, vol. 53. ACI Special Publication; 1977.

[12] Farrar CR, Bennett JG, Dunwoody WE, Baker WE. Static load cycle testing of a low-aspect-ratio six-inch wall TRG-type structure TRG-4-6 (1. 0, 0. 25) (No. NUREG/CR-5222; LA-11422-MS). Nuclear Regulatory Commission, Washington, DC (USA). Div. of Engineering; Los Alamos National Lab., NM (USA); 1989.

[13] Farrar CR, Bennett JG, Dunwoody WE, Baker WE. Low-aspect-ratio four-inch wall, TRG-type structure; 1990

[14] Farrar CR, Bennett JG, Dunwoody WE, Baker WE. Static load cycle testing of a very low-aspect-ratio six-inch wall TRG-type structure TRG-6-6 $(0.27,0.50)$ (No. NUREG/CR-5533; LA-11796-MS). Nuclear Regulatory Commission, Washington, DC (USA). Div. of Engineering; Los Alamos National Lab., NM (USA); 1990.

[15] Farrar CR, Baker WE, Dove RC. Static and simulated seismic testing of the TRG7 through-16 shear wall structures (No. NUREG/CR-5660; LA-11992-MS). Nuclear Regulatory Commission, Washington, DC (United States). Div. of Engineering; Los Alamos National Lab., NM (United States); 1991.

[16] Inada Y. Relationship between force and displacement in RC structures for nuclear reactors. Doctoral dissertation, PhD Thesis, Univ. of Tokyo; 1986.

[17] Shiga T, Shibata A, Takahashi J. Experimental study on dynamic properties of reinforced concrete shear walls. In: Proceedings, 5th world conference on earthquake engineering. Rome: International Association for Earthquake Engineering: 1973.

[18] Ogata K, Kabeyasawa T. Experimental study on the hysteretic behavior of reinforced concrete shear walls under the loading of different moment-toshear ratios. Trans, Jpn Concr Inst 1984;6:274-83.

[19] Benjamin JR, Williams HA. Reinforced concrete shear wall assemblies. Trans Am Soc Civ Eng 1961;126(2):114-45.

[20] Umemura H, Aoyama H, Ito M, Hosokawa Y. Aseismic characteristics of RC box and cylinder walls. In: Proceedings of the sixth world conference on earthquake engineering, New Delhi, India; 1976. p. 3144-9.

[21] Bertero VV. The response of shear walls subjected to dynamic loads. Doctoral dissertation, Massachusetts Institute of Technology; 1957.

[22] Antebi J. Model analysis of the response of shear walls to dynamic loads. Doctoral dissertation, Massachusetts Institute of Technology, Department of Civil and Sanitary Engineering; 1961.

[23] Gergely P. Seismic fragility of reinforced concrete structures and components for application to nuclear facilities. Division of Engineering Technology, Office of Nuclear Regulatory Research, US Nuclear Regulatory Commission; 1985.

[24] Ile N, Plumier C, Reynouard J. Test program on U-shaped walls leading to model validation and implication to design. In: Proceedings of the 12th European conference on earthquake engineering; 2002.

[25] Panagiotou M, Restrepo JI, Conte JP. Shake-table test of a full-scale 7-story building slice. Phase I: Rectangular wall. J Struct Eng 2010.

[26] Martinelli P, Filippou FC. Simulation of the shaking table test of a seven-story shear wall building. Earthq Eng Struct Dyn 2009;38(5):587.

[27] Moaveni B, He X, Conte JP, Restrepo JI, Panagiotou M. System identification study of a 7-story full-scale building slice tested on the UCSD-NEES shake table. J Struct Eng 2010.

[28] Luu H, Ghorbanirenani I, Léger P, Tremblay R. Numerical modeling of slender reinforced concrete shear wall shaking table tests under high-frequency ground motions. J Earthq Eng 2013;17(4):517-42.

[29] Ghorbanirenani I, Tremblay R, Léger P, Leclerc M. Shake table testing of slender RC shear walls subjected to eastern North America seismic ground motions. J Struct Eng 2011;138(12):1515-29.

[30] Waugh JD, Sritharan S. Lessons learned from seismic analysis of a seven-story concrete test building. J Earthq Eng 2010;14(3):448-69.

[31] Richard B, Martinelli P, Voldoire F, Corus M, Chaudat T, Abouri S, Bonfils N. SMART 2008: Shaking table tests on an asymmetrical reinforced concrete structure and seismic margins assessment. Eng Struct 2015;105:48-61.

[32] Richard B, Martinelli P, Voldoire T, Chaudat F, Abouri S, Bonfils N. SMART 2008: overview, synthesis and lessons learnt from the International Benchmark. Eng Struct 2016;106C:166-78.

[33] SMART; 2013. <wWw.SMART 2013.eu>.

[34] TAMARIS Experimental facility. <http://www-tamaris.cea.fr/>.

[35] Rapport DES. Proposition de modification de la règle fondamentale de sûreté 1.2. c relative à la détermination des mouvements sismiques à prendre en compte pour la sûreté des tranches nucléaires comportant un réacteur à eau 
sous pression, applicable à l'ensemble des installations nucléaires de base. Institut de Protection et de Sûreté Nucléaire; 1998.

[36] Gupta O, Lacoste AC. Prise en compte du risque sismique à la conception des ouvrages de génie civil d'installations nucléaire de base à l'exception des stockages à long terme des déchets radioactifs. Guide de l'Autorité de Sûreté Nucléaire. ASN/GUIDE/2/01. Autorité de Sûreté Nucléaire; 2006.

[37] Pedron C. Generation and characterization of synthetic signals: preliminary observations and developments. DEN technical report, SEMT/EMSI/RT/98-022/ A; 1998.

[38] Touboul F, Blay N, Sollogoub P. Seismic behaviour of piping systems. In: Paper K12/1. Transactions of the 15th int conf on struct mech reactor tech, Seoul, Korea; August 15-20, 1999.

[39] Chaudat Th, Richard B. SMART 2013 data acquisition project. DEN Technical report. DEN/DANS/DM2S/SEMT/EMSI/NT/13-003/B; 2013.

[40] Davis TL. 1994 Northridge earthquake. Nature 1994;372:167.

[41] NGA database. <http://peer.berkeley.edu/nga/>.

[42] CAST3M-CEA. <http://www-cast3m.cea.fr/>.

[43] Le Maoult A, Queval JC, Bairrao R. Dynamic interaction between the shaking table and the specimen during seismic tests. In: Advances in performancebased earthquake engineering. Netherlands: Springer; 2010. p. 431-40.
[44] Richard B, Ragueneau F. Continuum damage mechanics based model for quasi brittle materials subjected to cyclic loadings: formulation, numerical implementation and applications. Eng Fract Mech 2013;98:383-406.

[45] Menegotto M, Pinto PE. Slender RC compressed members in biaxial bending. J Struct Divis 1977;103(3):587-605.

[46] Rayleigh L. VIII. On the pressure developed in a liquid during the collapse of a spherical cavity. London, Edin, Dublin Philos Mag J Sci 1917;34(200):94-8.

[47] Crambuer R, Richard B, Ile N, Ragueneau F. Experimental characterization and modeling of energy dissipation in reinforced concrete beams subjected to cyclic loading. Eng Struct 2013;56:919-34.

[48] Heylen W, Sas P. Modal analysis theory and testing. Katholieke Universtei Leuven, Departement Werktuigkunde; 2006

[49] Chaudat Th. SMART 2013 Test report. DEN Technical report. DEN/DANS/DM2S/ SEMT/EMSI/NT/14-019/A; 2014.

[50] Grünthal G, Levret A. L'échelle Macrosismique Européenne, European Macroseismic Scale 1998. Cahiers du Centre Européen de Géodynamique et de Séismologie 2001; 19. 